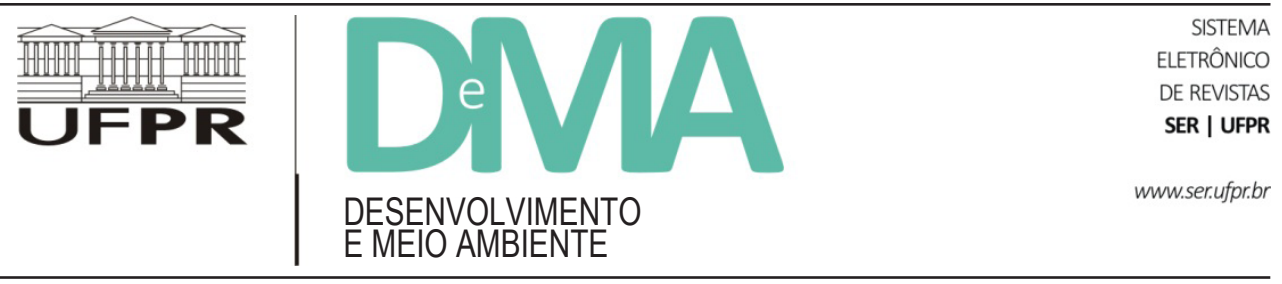

\title{
Diagnóstico da zona de uso aquaviário e portuário de Itajaí - ZUAP (SC): bases para planejamento espacial marinho (PEM) local
}

\section{Diagnosis of the Port and Waterway Area of Itajaí - PWAI (SC): Bases for the Local Marine Spatial Planning (MSP)}

\author{
Fabiana Regina GERN ${ }^{*}$, Camila LONGARETE ${ }^{1}$, Marina CHRISTOFIDIS ${ }^{2}$, Fabiano Duarte ROSA ${ }^{3}$, Luiz \\ Rodrigo MAÇANEIRO ${ }^{4}$, Marcus POLETTE ${ }^{1}$ \\ ${ }^{1}$ Universidade do Vale do Itajaí (UNIVALI), Itajaí, SC, Brasil. \\ ${ }^{2}$ Secretaria do Patrimônio da União de Santa Catarina (SPU/SC), Florianópolis, SC, Brasil. \\ ${ }^{3}$ Instituto Federal de Santa Catarina (IFSC), Itajaí, SC, Brasil. \\ ${ }^{4}$ Fundação Pró-Tamar, Itajaí, SC, Brasil. \\ *E-mail de contato: fabigern@gmail.com
}

Artigo recebido em 28 de julho de 2016, versão final aceita em 8 de março de 2017.

RESUMO: $\quad$ Nos últimos anos, a instalação de novos empreendimentos na região da foz do Rio Itajaí-Açu passou por uma forte pressão devido à inserção de novos estaleiros e marinas, além da expansão portuária dos dois lados do estuário. Logo, o uso da zona aquaviária e portuária de Itajaí torna-se mais intenso, consequentemente, essa situação leva a problemas e conflitos, os quais surgem devido à ineficiente aplicação de políticas públicas de planejamento e ordenamento territorial. O presente trabalho realiza um diagnóstico da zona de uso aquaviário e portuário (ZUAP) de Itajaí, a fim subsidiar a gestão integrada local. Para isso, o Planejamento Espacial Marinho (PEM) surge como um instrumento inovador de apoio à gestão, que tem por objetivo ordenar e zonear o ambiente, além de entender os problemas e conflitos, oportunizando mudanças futuras de forma consorciada. A metodologia utilizada baseia-se no Guia da UNESCO, o qual apresenta 10 passos para execução do PEM e constitui-se num processo de natureza adaptativa e contínua. A metodologia adaptada utilizada neste estudo traz uma abordagem de análise territorial de baixo custo e proporciona a integração de visões interssetoriais. A ZUAP se constitui numa zona de abrigo à navegação, o que propicia o desenvolvimento de atividades conflituosas e relacionadas a essa característica. Os municípios que circundam a ZUAP apresentam seu desenvolvimento econômico relacionado diretamente com os setores portuários, pesqueiros, da construção e reparo naval, além do turismo e lazer. O desafio para a política bem-sucedida em PEM no âmbito do estuário do Rio Itajaí-Açú encontra-se na montagem de todas as peças do quebra-cabeça, trazendo a conciliação entre investigação científica e soluções práticas. Por se tratar de uma abordagem holística, este diagnóstico pode ser 
considerado como o primeiro passo para o desenvolvimento de um plano de uso múltiplo no baixo estuário do Rio Itajaí-Acú.

Palavras-chaves: planejamento espacial marinho; zona de uso aquaviário e portuário; Rio Itajaí-Açu.

ABSTRACT: In recent years, the installation of new enterprises in the Itajaí-Açú River outfall underwent a strong pressure due to the insertion of new shipyards and marinas, as well as port expansion on both sides of the estuary. Thus the use of the waterway and port area of Itajaí becomes more intense, therefore, this situation leads to problems and conflicts, which arise due to the inefficiency in applying public planning policies and territorial planning. Therefore, this study aims to diagnose the Port and Waterway Area of Itajai (PWAI), in order to support integrated management. Marine Spatial Planning (MSP) emerges as an innovative tool to support management, which aims to order and zone the environment, besides seeking to understand the problems and conflicts, providing opportunities for future changes to happen in a jointly manner. The methodology is based on UNESCO's guide, which presents ten steps and constitutes an adaptive and continuous process. The adapted methodology used in this study brings a low cost approach to territorial analysis and provides the integration of intersectoral visions. PWAI is considered a shelter area for navigation which enables the development of correlated and conflicting activities. The cities surrounding the $P W A I$ have their economic development directly related to the port sector, fishing, shipbuilding and repair industry, as well as tourism and leisure. The challenge for the successful policy in MSP within the estuary of the Itajaí-Açú river lies in the assembly of all pieces of the puzzle, bringing the reconciliation between scientific research and practical solutions. Because of the holistic approach, this diagnosis can be considered as the first step to the development of a multiple use plan in the low estuary of Itajaí-Açú river.

Keywords: Marine Spatial Planning; port and waterway area; Itajaí-Açú river.

\section{Introdução}

O estuário do Rio Itajaí-Açu apresenta inúmeros empreendimentos intimamente vinculados às atividades náutica, marítima e naval. Usos tais como transporte marítimo, recreação marinha, pesca industrial e artesanal, por exemplo são atividades em intenso crescimento, o que acarreta uma competição por espaço no ambiente aquático (Huang et al., 2015). Desse modo, os conflitos de uso na zona aquaviária e portuária de Itajaí e Navegantes tornam-se mais complexos de serem mediados devido à ausência de um Planejamento Espacial Marinho. Isso ocorre devido à falta de entendimento de suas potencialidades como instrumento de apoio à gestão e também ao fato de ser pouco conhecido pelas autoridades. Tal cenário ainda é agravado, pois a procura por bens e serviços de uma área estuarina geralmente excede a sua capacidade de atender a todas as demandas de forma simultânea (Prestelo \& Viana, 2016).

Alguns países já designam ou ordenam o espaço marinho para inúmeras atividades, incluindo o transporte de passageiros, o desenvolvimento da indústria de oleo e gás, a geração de energia renovável offshore, a aquicultura offshore, o despejo de efluentes e as áreas marinhas protegidas (Portman et al., 2009). Entretanto, esse tipo de zoneamento é realizado normalmente por meio de uma base de setor a setor, sem muita consideração sobre os efeitos dessas ações, tanto considerando as atividades humanas como o ambiente marinho (Crowder et al., 2006). Portanto, o Planejamento Espacial Marinho (PEM) foi projetado para substituir o sistema de decisão setorial e fragmentada (Katsanevakis et al., 2011). Por muito tempo, o transporte marítimo, a pesca, a geração de energia, o turismo e o meio ambiente foram geridos separadamente, às vezes 
levando a ineficiências, incoerências e conflitos de uso.

Segundo Ehler \& Douvere (2009), o Planejamento Espacial Marinho (PEM) é um processo público que analisa e aloca a distribuição espacial e temporal das atividades humanas em áreas marinhas, para alcançar os objetivos ecológicos, econômicos e sociais, que normalmente são especificados por meio de um processo de carácter político. É uma forma de gestão inovadora e que vem sendo implantada ao redor do planeta nos últimos anos (Calado et al., 2010, Suares-de Vivero \& Mateos, 2012). Oferece aos países um quadro operacional para manter o valor de sua biodiversidade marinha e, ao mesmo tempo, permite o uso sustentável do potencial econômico de águas territoriais.

Já em 1997, Polette justificava que, para o uso mais racional dos recursos naturais da zona costeira e marinha, de forma a conduzir uma política satisfatória de uso dos recursos vivos, existe uma necessidade intrínseca de regulamentar a utilização desses usos, bem como a de definir a extensão destes usos para fins de gerenciamento costeiro integrado, pois o uso e as pressões os diversos setores tendem a aumentar em consequência do próprio crescimento demográfico mundial. O caráter tridimensional do mar faz com que este desafio seja ainda mais difícil, pois é possível ter na mesma área diferentes atividades ocorrendo simultaneamente em diferentes profundidades. Por exemplo, projetos de energia eólica offshore podem estar combinados com projeto de aquicultura em um mesmo local. Extração de areia, pesca e exercícios militares também podem ser combinados no mesmo espaço, mas não ao mesmo tempo (Plasman, 2008). Segundo Ehler (2008), Planejamento Espacial Marinho é uma ideia em evolução, visto que o PEM cobre quase 10\% das Zonas Econômicas Exclusivas - ZEE's do planeta,sendo previsto que, até 2025, irá cobrir mais de 30\% dessas áreas (Ehler, 2013).

Nos últimos anos, vários países começaram a usar o termo e a teoria PEM para reduzir os conflitos e utilizar os recursos costeiros e marinhos de forma mais sustentável (Jay et al., 2016; Smythe, 2017). Um dos exemplos mais conhecidos é o sistema de zoneamento da Grande Barreira de Corais na Austrália, que, em sua abordagem, permite múltiplas atividades humanas, incluindo a pesca e o turismo, enquanto simultaneamente proporciona um elevado nível de proteção em áreas específicas (McCook et al., 2010). Outras iniciativas incluem PEM, como o Santuário Nacional Flórida Keys nos EUA; iniciativa de gestão na costa do Canadá e o Plano de Gestão de Recursos nas Filipinas (Douvere et al., 2007). A maior parte desses exemplos é inspirada principalmente pelas forças relacionadas a questões de conservação da natureza e não necessariamente por considerações relacionadas com a gestão de conflitos entre diferentes atores. $\mathrm{O}$ zoneamento em que a proteção ambiental é harmonizada com usos do mar é provavelmente a mais eficaz abordagem para mitigar e, possivelmente, reverter a extensa e crescente forma de impactos humanos sobre ecossistemas marinhos e costeiros (Agardy, 2010). Entretanto, em alguns casos de PEM, a saúde do ecossistema pode não ser o objetivo primário. $\mathrm{O}$ bem-estar econômico também é um objetivo importante nas iniciativas de planejamento marinho (Huang et al., 2015).

O zoneamento ou alocação de espaço para usos de atividades específicas ou funções de não uso pode aumentar a segurança para os investidores e reduzir atrasos nos licenciamentos ambientais das propostas. Objetivos sociais no planejamento marinho incluem a redução de conflitos e melhoria das relações com a comunidade, sendo que essas 
metas podem ser atingidas por meio da educação, envolvimento e colaboração da sociedade para identificar e buscar interesses comuns.

Vários países europeus, por exemplo, por sua própria iniciativa ou impulsionados pela legislação e política europeias, têm alcançado liderança global na avaliação e implementação de PEM em um contexto mais amplo. A Holanda desenvolveu um Plano de Gestão Integrado para o Mar do Norte, que inclui um ordenamento do território, voltado para utilização economicamente eficiente do seu espaço marítimo (IMPNS, 2015). A costa da Alemanha estendeu seu planejamento espacial para o mar territorial, e a Lei do Ordenamento do Território Federal foi alterada para estender as competências setoriais (Gee et al., 2004). Informações sobre o PEM no Brasil são escassas; apenas estudos pontuais que mencionam esse termo foram publicados: Mazzer (2013) apresentou um plano de ordenamento marinho para o Município de Florianópolis, Prestelo \& Viana (2016) analisaram o conflito de uso na Baía de Guanabara/RJ e Piazza \& Polette (2015) analisaram o ordenamento para transatlânticos em Porto Belo/SC.

Nos últimos anos, a instalação desordenada de novos empreendimentos na região da foz do Rio Itajaí-Açu passou por uma forte pressão decorrente da inserção de novos estaleiros e marinas, além da expansão portuária dos dois lados do estuário, incluindo os Municípios de Itajaí e Navegantes. Logo, essa região estuarina entre os municípios torna-se um importante exemplo do intenso uso, o que amplia a possibilidade de potenciais problemas e conflitos, resultantes da ineficaz aplicação de políticas públicas de planejamento e ordenamento territorial no ambiente costeiro.

O presente trabalho busca estabelecer um diagnóstico atual da zona de uso aquaviário e portuário de Itajaí, a fim de subsidiar seu ordenamento e gestão, além de entender seus problemas e conflitos. En- tende-se por ordenamento a iniciativa de ordenar os distintos usos no espaço, ao passo que gestão é a sistematização das ações para se atingir o ordenamento.

Cabe ressaltar que o Porto de Itajaí apresenta um Plano de Desenvolvimento e Zoneamento (PDZ), conforme prevê a nova Lei dos Portos (Lei $n^{0} 12.815 / 2013$ - Secretaria de Portos da Presidência da República - SEP). O PDZ é um instrumento de planejamento operacional da Administração Portuária, que compatibiliza as políticas de desenvolvimento urbano dos municípios, do estado e da região onde se localiza o porto, visando, no horizonte temporal, o estabelecimento de ações e de metas para a expansão racional e a otimização do uso de áreas e instalações do porto, com aderência ao Plano Nacional de Logística Portuária - PNLP e respectivo Plano Mestre. Já a Portaria no 414/ 2009 - SEP estabelece as diretrizes, os objetivos gerais e os procedimentos mínimos para a elaboração do Plano de Desenvolvimento e Zoneamento Portuário. Na prática, o PDZ foca na área portuária terrestre, especificamente em áreas dentro do porto organizado (Decreto $\mathrm{s} / \mathrm{n}^{\circ}$ de 16 de março de 2005). O que é exigido para a publicação de um PDZ não é satisfatório em relação aos usos do ambiente estuarino. Logo, torna-se fundamental a inserção de um Planejamento Espacial Marinho no âmbito da ZUAP, pois este tem o papel de integrar o zoneamento com as ações de gestão.

$\mathrm{O}$ estuário-foco da pesquisa abrange o maior polo pesqueiro nacional e o terceiro maior porto em movimentação de carga, ou seja, usos intensos que ocorrem em pequena escala evidenciam a importância da aplicação do PEM nessa região do Brasil. Assim, este trabalho contribui com bases científicas diferenciadas para o planejamento e ordenamento de uso do espaço e dos recursos aquáticos da região, bem como serve como modelo para aplicação da metodologia do PEM em ambientes estuarinos. 


\section{Metodologia}

\section{1. Área de estudo}

O Complexo Portuário de Itajaí situa-se no maior rio de Santa Catarina, o Rio Itajaí-Açu. Situado entre os Municípios de Itajaí e Navegantes, o rio caracteriza-se pela intensa movimentação de cargas unitizadas (contêineres), além de carga geral e refrigerada, sendo o terceiro maior porto em movimentações de cargas do Brasil (Polette et al., 2012). Os citados municípios também formam o maior polo pesqueiro do País, agregando atividades de pesca artesanal e industrial, de recepção e beneficiamento de pescado, entre outras atividades.

A área de estudo corresponde à parte aquática e à zona de uso aquaviário e portuário (zoneamento proposto no plano estadual de gerenciamento costeiro - GERCO/SC, 2009) do litoral de Itajaí e
Navegantes e suas margens. $\mathrm{O}$ recorte adotado na margem considera a faixa de 33 metros de terreno de marinha. O Decreto-Lei n ${ }^{\circ} 9.760 / 1946$, em seu art. $2^{\circ}$, considera terrenos de marinha as terras em uma profundidade de 33 (trinta e três) metros, medidos horizontalmente, para a parte da terra, da posição da linha do preamar-médio de 1831. Por existirem densas discussões acerca da demarcação dessa linha de preamar-médio de 1831 (Lima \& Philips, 2005), optou-se por utilizar a linha de costa atual.

A área de estudo foi subdivida em três subáreas para melhor representação gráfica dos resultados: $1^{\text {a }}$ - da ponte da BR 101 até a balsa, como o Setor 1; $2^{\text {a }}$ - do trecho da balsa até os molhes, como o Setor 2 ; e $3^{\text {a }}$ - a porção marítima além dos molhes, correspondente ao Setor 3 ou Área Externa (Figura 1).

O Setor 1 caracteriza-se pela porção a montante do Rio Itajaí-açú, onde se localizam as principais entidades do setor de estaleiros e da pesca industrial. É a parte de pouco acesso às grandes embarcações.

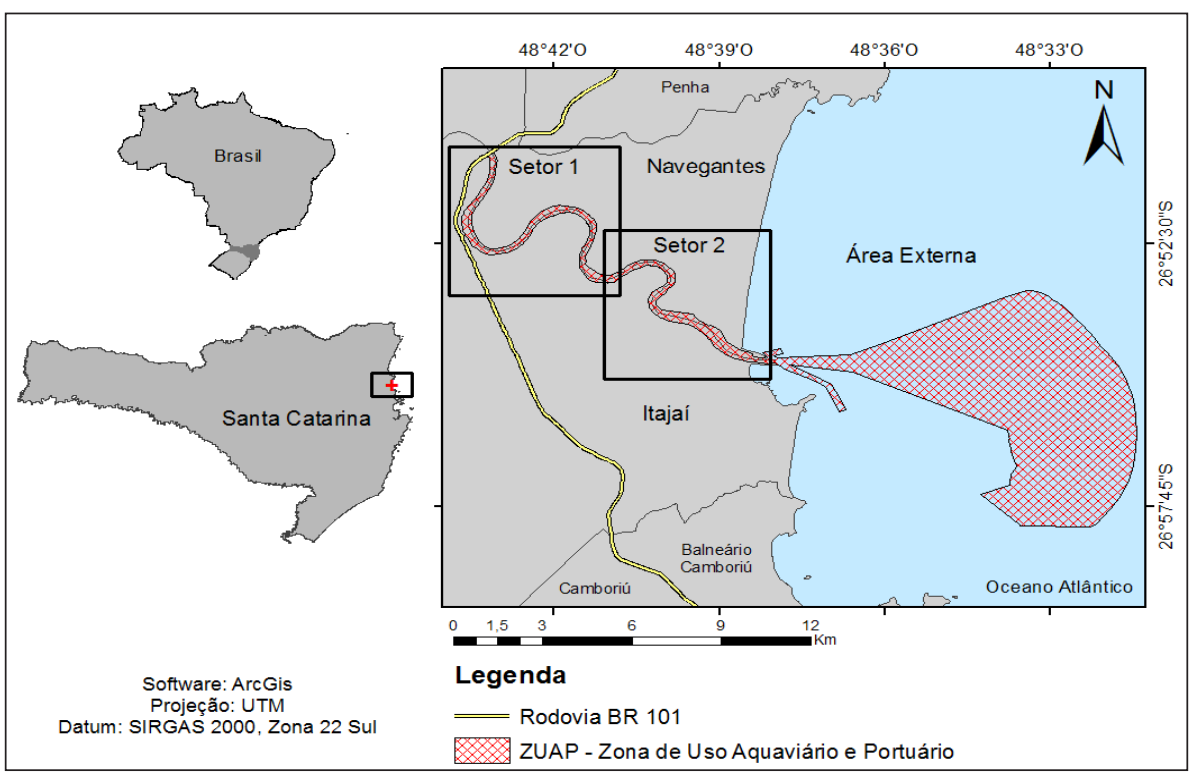

FIGURA 1 - Mapa com a localização da área de estudo, apresentando as subdivisões de análise em Setor 1, Setor 2 e Setor 3 (Área Externa). 
O Setor 2 caracteriza-se por ser o mais movimentado, pois ali se encontram a Portonave (porto privado em Navegantes) e, logo a sua frente, o Porto Municipalizado de Itajaí. Nesse setor, encontram-se ainda o terminal de passageiros de transatlântico, o Ferry-boat (que faz a intensa travessia entre os Municípios de Itajaí e Navegantes); as principais instituições do estuário, como a Delegacia de Portos e Costas da Marinha; o Centro Nacional de Pesquisa e Conservação da Biodiversidade Marinha do Sudeste e Sul (Cepsul) e a Marina privada de Itajaí. No Setor 2, ainda estão situados os bairros do centro de ambos os municípios, além de inúmeras áreas de atracação de embarcações de pescadores artesanais da região.

O Setor 3 caracteriza-se por ser a área externa ao rio, onde ocorrem atividades como a pesca artesanal, áreas de bota-fora, áreas de fundeio, além da sinalização do canal de acesso ao porto e intenso tráfego aquaviário.

\subsection{Procedimento de coleta e análise de dados}

Para o desenvolvimento do método, houve a adaptação do Guia de Planejamento Espacial Marinho da Comissão Oceanográfica Internacional (COI/UNESCO) como base para um ordenamento marinho em área estuarina. O PEM possui 10 passos para sua execução, os quais foram baseados nas diversas experiências desenvolvidas ao redor do planeta. Relevante destacar que os passos para o desenvolvimento do PEM estão interligados e não necessariamente ocorrem de forma linear, pois são susceptíveis a modificações. O planejamento é um processo dinâmico, e planejadores devem estar abertos às mudanças que se adaptam a esse processo e que também evolui ao longo do tempo (Ehler \& Douvere, 2009).
A presente proposta focou principalmente no $5^{\circ}$ passo da estrutura do PEM, porém, os passos $1^{\circ}$, $3^{\circ}$ e $4^{\circ}$ da metodologia também foram considerados (Figura 2). As ações estruturantes da metodologia adaptada foram: (a) observação in loco, (b) análise das imagens de satélite, (c) entrevistas, (d) levantamento e espacialização das condicionantes de ordem legal, além do (e) levantamento de dados secundários.

(a) Foram realizadas três saídas a campo navegando pelo rio, dos molhes até a BR 101, nos dias 01/12/2015, 27/01/2016 e 21/05/2016, para reconhecimento e delimitação dos distintos usos, tanto das margens quanto na parte aquática do Rio Itajaí-Açu. Foram feitos registros fotográficos, além de vídeos das margens;

(b) A imagem de satélite utilizada para análise foi coletada no Google Earth Pro em março de 2015, a uma resolução de 4800x3190 pixels, extraídas na altura de $2 \mathrm{~m}$. Foi realizada seu georreferenciamento no software ArcGis 10.

(c) Foram realizadas 29 entrevistas (entre março a maio de 2016) com diversas lideranças de instituições dos setores público e privado, especialmente aquelas envolvidas no uso da área de estudo (stakeholder-Tabela 1). A pessoa escolhida para representar a instituição foi aquela de nível de liderança mais alto possível, portanto, donos, presidentes, diretores, delegado, gerentes, secretários municipais foram entrevistados. As entrevistas foram embasadas em questionários semiestruturados, nos quais os entrevistados receberam uma imagem de satélite da área de estudo (Google Earth Pro), sobreposta por filme plástico (transparente), em que poderiam desenhar polígonos indicadores dos limites de atuação de sua instituição sobre a parte aquática. Essa técnica é conhecida como mapa mental (Archela et al., 2004). Quanto ao tamanho da amostra, foi utilizada a técnica da saturação, que, segundo Bitsch (2005) e Fontanella et al. (2008), é 


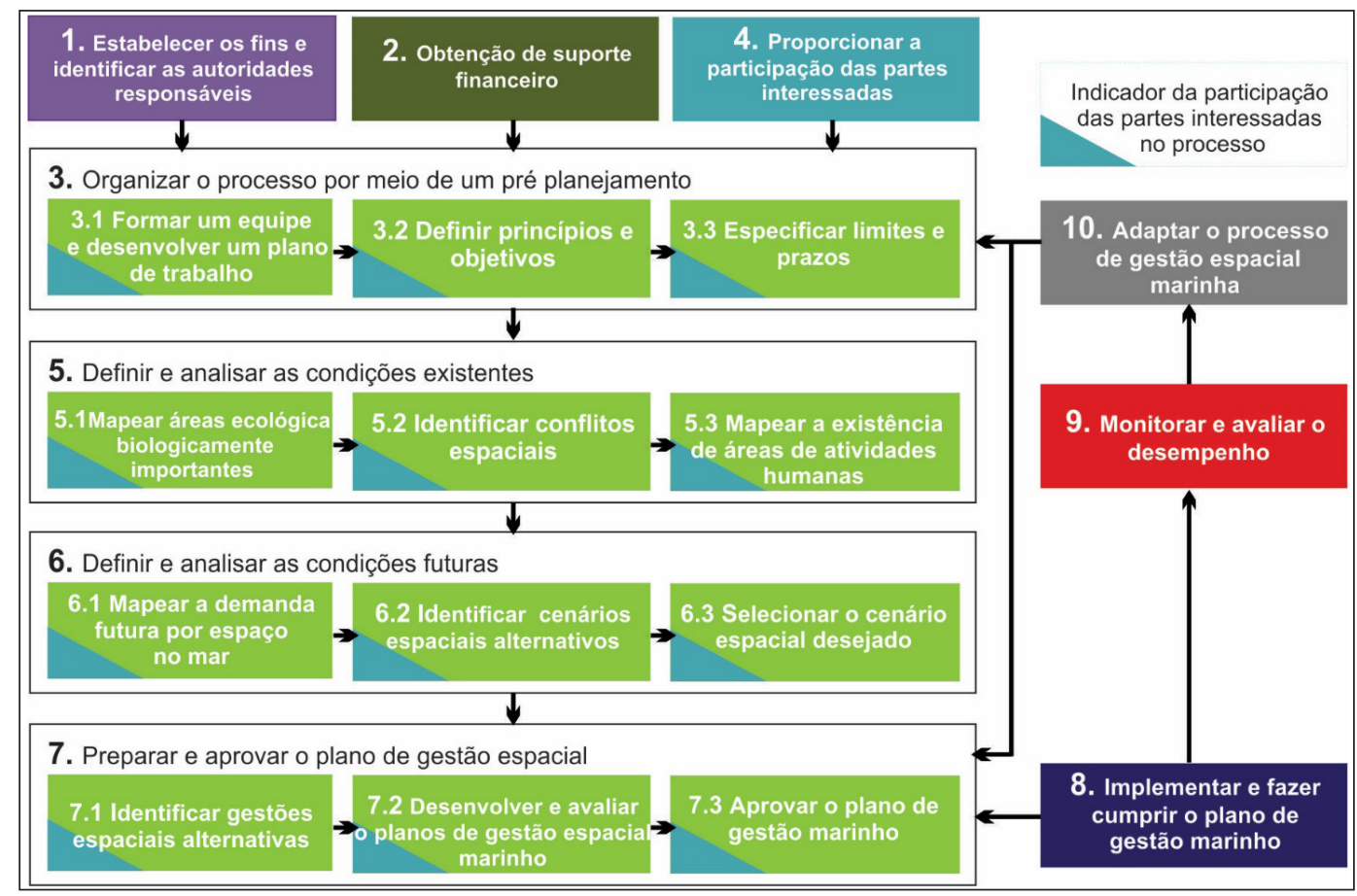

FIGURA 2 - Dez passos fundamentais do Planejamento Espacial Marinho, UNESCO. FONTE: Adaptado de Ehler \& Douvere (2009).

TABELA 1 - Relação dos atores entrevistados. Atores grifados foram os que produziram o mapa mental de relação de uso. As distintas cores foram relacionadas aos distintos usos apresentados na Tabela 3.

\begin{tabular}{|c|c|c|}
\hline Agências Governamentais & Iniciativa Privada & Sociedade Civil Organizada \\
\hline $\begin{array}{c}\text { Centro Nacional de Pesquisa e Conservação da } \\
\text { Biodiversidade Marinha do Sudeste e Sul (Cepsul) }\end{array}$ & ECOSORB Tecnologia e Proteção Ambiental & Tamar \\
\hline $\begin{array}{c}\text { Instituto Brasileiro de Meio Ambiente e Recursos } \\
\text { Naturais Renováveis (IBAMA) }\end{array}$ & Saam Smit (Rebocadores) & $\begin{array}{c}\text { Sindicato dos Armadores e das } \\
\text { Indústrias da Pesca de Itajaí e } \\
\text { Região (SINDIPI) }\end{array}$ \\
\hline Secretaria do Patrimônio da União (SPU/ SC) & Gomes da Costa Alimentos (pescados) & $\begin{array}{l}\text { Associação Náutica de Itajaí } \\
\text { (ANI) }\end{array}$ \\
\hline Instituto Federal de Santa Catarina (IFSC) & Detroit Brasil (estaleiro) & \\
\hline Fundação de Meio Ambiente de Itajaí (Famai) & Navegação Santa Catarina (Ferry boat e balsa) & \\
\hline $\begin{array}{c}\text { Fundação Municipal de Meio Ambiente de } \\
\text { Navegantes (Fuman) }\end{array}$ & Estaleiro Maccarini & \\
\hline Itajaí e Navegantes Práticos e Serviços de Praticagem & Comércio e Indústria de pescados Kowalsky & \\
\hline \multirow[t]{2}{*}{ Rádio Costeira Itajaí } & Marina Itajaí & \\
\hline & Universidade do Vale do Itajaí (UNIVALI) & \\
\hline
\end{tabular}


usada para estabelecer ou fechar o tamanho final de uma amostra em estudo, interrompendo a captação de novos componentes, quando os dados obtidos passam a representar, na opinião do pesquisador, suficiência para atingir os objetivos. Além disso, as entrevistas serviram como instrumento de análise sobre a percepção dos atores em relação ao PEM.

(d) Foi realizada uma ampla compilação da legislação acerca do tema.

(e) Informações oriundas de diversos estudos efetuados por instituições governamentais e não governamentais, bem como de pesquisa acadêmica.

Cabe destacar que a aplicação do método não é linear, nem todas as ações ocorreram de forma lógica, muitas ocorreram simultaneamente e outras de forma dependente. A integração de metodologias está apresentada na Tabela 2, expondo os passos do PEM abordados neste artigo.

Em uma etapa subsequente, foram mapeados em ArcGIS os diferentes usos setoriais, constituindo um Sistema de Informações Geográficas (SIG), tendo como base a construção de polígonos de delimitação de áreas, com legendas específicas e definidas a partir de critérios de classificação, tanto da margem quanto da parte aquática. A criação de classificações foi um elemento importante para padronizar o mapeamento temático. Para classificação de uso e ocupação, foram utilizados os critérios descritos na Tabela 3.

TABELA 2 - Integração entre as metodologias do PEM, expressas na Figura 2, e ações estruturantes do artigo.

\begin{tabular}{|c|c|c|}
\hline \multicolumn{2}{|c|}{ Metodologia PEM (UNESCO) } & Ações estruturantes \\
\hline \multicolumn{2}{|c|}{ Passo 1 - Estabelecer os fins e identificar as autoridades responsáveis } & $\mathrm{a} ; \mathrm{c} ; \mathrm{d} ; \mathrm{e}$ \\
\hline $\begin{array}{l}\text { Passo } 3 \text { - Organizar o processo por meio } \\
\text { de um pré-planejamento }\end{array}$ & 3.2 Definir princípios e objetivos & $\mathrm{c} ; \mathrm{e}$ \\
\hline \multicolumn{2}{|c|}{ Passo 4 - Proporcionar a participação das partes interessadas } & $\mathrm{c}$ \\
\hline \multirow{2}{*}{$\begin{array}{l}\text { Passo } 5 \text { - Definir e analisar as condições } \\
\text { existentes }\end{array}$} & 5.1 Mapear áreas ecológica e biologicamente importantes & $\mathrm{a} ; \mathrm{b} ; \mathrm{c} ; \mathrm{d} ; \mathrm{e}$ \\
\hline & 5.2 Identificar conflitos espaciais & $\mathrm{a} ; \mathrm{b} ; \mathrm{c} ; \mathrm{d} ; \mathrm{e}$ \\
\hline
\end{tabular}

TABELA 3 - Descrição dos critérios de subclassificação dos usos da área de estudo. Cada cor representa um uso, sendo que cada uma está relacionada aos mapas temáticos apresentados nos resultados.

\begin{tabular}{|c|c|c|}
\hline Classificação & Subclassificação & Critérios \\
\hline \multirow{3}{*}{$\begin{array}{l}\text { Margens } \\
(33 \mathrm{~m})\end{array}$} & Cobertura vegetada & $\begin{array}{l}\text { Zona com a presença de flora sem infraestruturas. Inclui: cobertura de mangue, marisma } \\
\text { ou grandes árvores; cobertura de hibisco, terrenos baldios; rizicultura e área de pastagem. }\end{array}$ \\
\hline & $\begin{array}{l}\text { Urbana com relação de uso } \\
\text { direto }\end{array}$ & $\begin{array}{l}\text { Zona com a presença de infraestrutura que apresenta relação direta de uso com o rio. } \\
\text { Inclui: transporte de carga, transporte de veículos e passageiros, área militar, pesca, } \\
\text { turismo e lazer, extração de areia, construção e reparo naval. }\end{array}$ \\
\hline & Urbana sem relação de uso & $\begin{array}{l}\text { Zona com a presença de infraestrutura que não apresenta relação direta de uso com o rio. } \\
\text { Inclui: áreas residenciais, sedes de órgãos públicos, cemitério, ou seja, instituições que } \\
\text { logisticamente não necessitam da proximidade com o rio. }\end{array}$ \\
\hline \multirow[b]{4}{*}{ Zona interna } & Pesca Industrial & $\begin{array}{l}\text { Zona com a presença de embarcações típicas de pesca industrial (maiores que } 20 \text { de } \\
\text { Arqueação Bruta - AB). Proximidade com empresas de processamento de pescado. }\end{array}$ \\
\hline & Pesca Artesanal & Zona com a presença de embarcações típicas de pesca artesanal (menor que 20 AB). \\
\hline & Mineração & Zona com a presença de dragas específicas para retirada de areia. \\
\hline & Estaleiros & $\begin{array}{l}\text { Zona com a presença de embarcações sendo construídas e/ou em manutenção. Presença } \\
\text { de carreiras e docas nas margens. }\end{array}$ \\
\hline
\end{tabular}


Quando analisados por meio de seus diferentes setores, os usos da atividade de pesca, tanto artesanal quanto industrial, que ocorrem nos setores 1 e 2 (Figuras 4 e 5), são relacionados apenas à presença de embarcações e não à captura do pescado em si. Apenas no setor externo (Figura 6), a classificação de pesca artesanal relaciona-se à captura, que, nesse caso, é principalmente a pesca de arrasto de camarão.

\section{Resultados e discussão}

\subsection{Análise da zona aquática (Passo 5 , Figura 2)}

A pressão sobre as regiões estuarinas vem aumentando ao longo das últimas décadas (Halpern, et al., 2008; Prestelo \& Viana, 2016). Os estuários são sistemas ricos em recursos, com uma enorme gama de atividades econômicas integradas e diversos atores envolvidos. Por se tratar de um ambiente de múltiplas escalas e usos, é anunciado que surjam conflitos e problemas. Há, portanto, uma necessidade intrínseca de esses ambientes serem abordados pelo PEM, que objetiva ordenar o ambiente, além de entender os problemas e conflitos, oportunizando assim mudanças futuras de forma consorciada. Prestrelo \& Viana (2016) mencionam que o primeiro passo para o desenvolvimento de um PEM em um estuário de múltiplos usos é identificar e mapear os usos existentes, os conflitos e legislações, considerando a sua natureza multissetorial. Foi feito exatamente isso nesta pesquisa.

A Zona de Uso Aquaviário e Portuário (ZUAP) do baixo estuário do Rio Itajaí-Açu (a largura média do rio no baixo estuário é entre 200 a $300 \mathrm{~m}$ ) se constitui numa zona de abrigo à navegação, o que propicia o desenvolvimento de atividades re- lacionadas a essas características, sendo registrados principalmente usos relacionados aos setores da pesca, dos portos, da construção e reparo naval e do turismo e lazer (Figuras 3, 4 e 5). Entretanto, analisando-se os usos citados pelo Guia de Planejamento Espacial Marinho (Ehler \& Douvere, 2009) na região do estudo, foi possível registrar ainda o uso militar, transporte de veículos e passageiros (ferry boat e balsa) e a mineração (Figuras 4 e 5). É importante destacar que a atividade do tráfego aquaviário é intensa e ocorre em toda a área analisada.

\subsubsection{Setor 1}

O setor a montante do rio é caracterizado pelo uso principalmente da pesca industrial e pelos estaleiros. Outro uso da zona aquática também citado pelo Guia de PEM (Ehler \& Douvere, 2009) e encontrado nesse setor é a extração de areia do leito do rio, destinada à construção civil (Figura 3). $\mathrm{Na}$ categoria de estaleiro, estão incluídos aqueles voltados às embarcações de pesca (artesanal e industrial), e às embarcações de apoio marítimo offshore.

Nas margens do Município de Navegantes, observa-se a ocorrência de bombeamento da água do rio para abastecimento das áreas de rizicultura nas proximidades. Silva \& Pereira Filho (2010) citaram que, ao longo do ciclo do arroz, a água é continuamente captada do estuário para enchimento dos campos de arroz no seu plantio e posteriormente para manutenção das culturas, sendo parcialmente devolvida ao corpo d'água, após ser utilizada. Outro uso para essas captações de água são as indústrias (Rorig, 2005), que se situam no baixo estuário do Rio Itajaí-Açu, majoritariamente constituídas por empresas de processamento de pescado. A captação de água em outros pontos do rio pode estar relacionada também ao sistema hidráulico preventivo 
de combate a incêndios. Conforme o parágrafo único do artigo 20 das normas de segurança contra incêndio do estado (IN 007/DAT/CBMSC, 2014), é possível o uso de água de manancial natural como reservatório. Já nas margens de Itajaí, próximo à balsa, situa-se o parque náutico Odílio Garcia, região considerada ideal para contemplação da natureza, com a presença de pescadores esportivos, caracterizando a presença do setor de turismo e lazer. Na região a montante do Rio Itajaí-Açu, foram registradas cinco carcaças de embarcações abandonadas e parcialmente submersas. Segundo Basso (2012), o Rio Itajaí-Açu está sujeito a virar um "cemitério de embarcações" devido à falta de controle ambiental dos órgãos e de definição de responsabilidades no ciclo final de vida das embarcações.

\subsubsection{Setor 2}

O setor da foz do Rio Itajaí-Açú é a área que apresenta a maior diversidade de usos, tais como aqueles relacionados à pesca artesanal e industrial, aos maiores terminais portuários, ao turismo e lazer, ao transporte de veículos e passageiros (ferry boat), à construção e reparo naval, à área militar e apoio à praticagem (Figura 4). É nessa região em que historicamente os Municípios de Itajaí e Navegantes iniciaram o seu processo de ocupação urbana (Goulart Filho, 2008). Nesse setor, está inserida a poligonal do Porto Organizado, que, conforme prevê a Lei dos Portos (Lei no 12.815/2013), é o espaço geográfico onde a autoridade portuária detém o poder de administração do porto público. Os terminais de uso privado, em regra, devem lo-

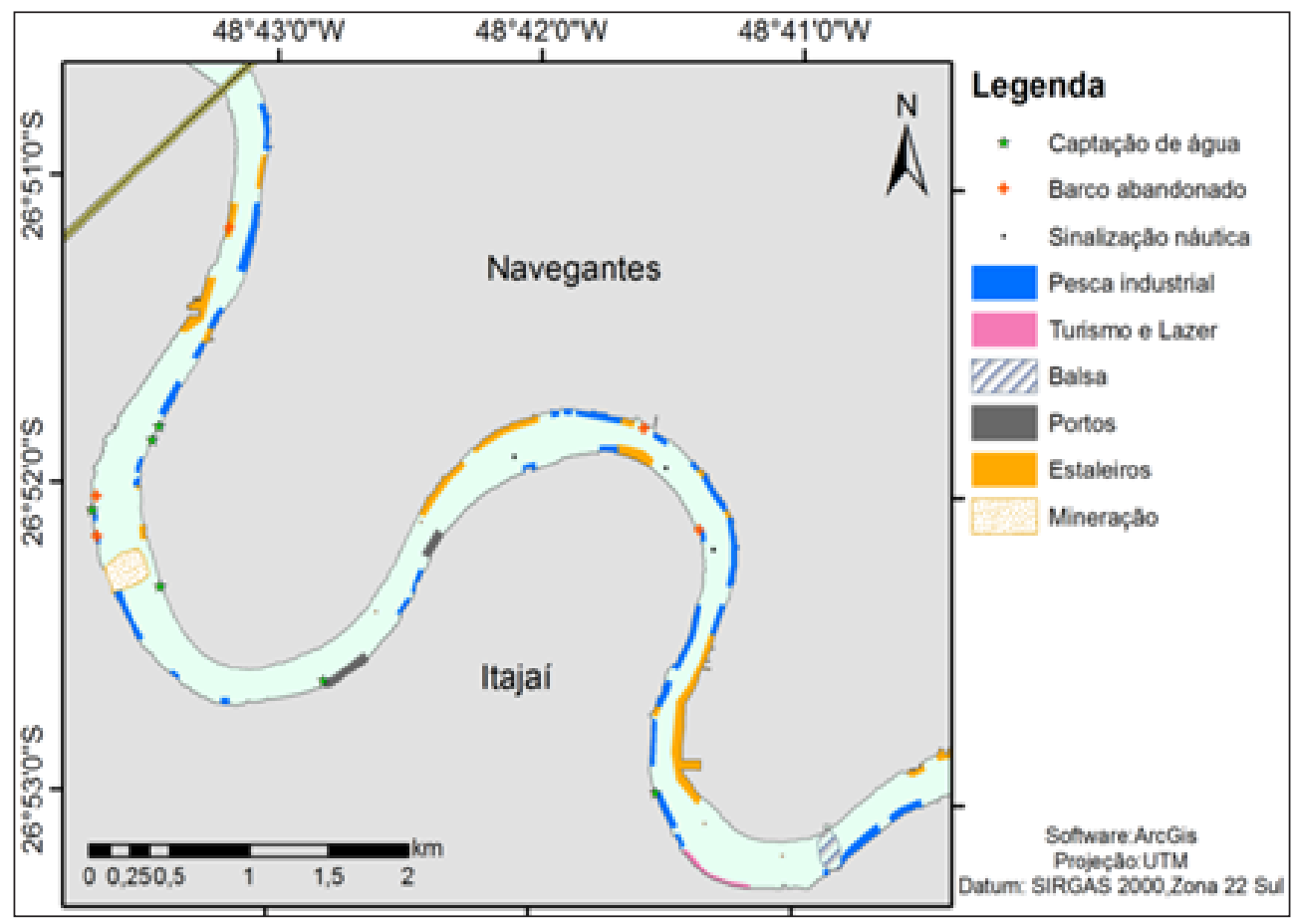

FIGURA 3 - Mapa temático de uso e ocupação da zona aquática do setor 1. 


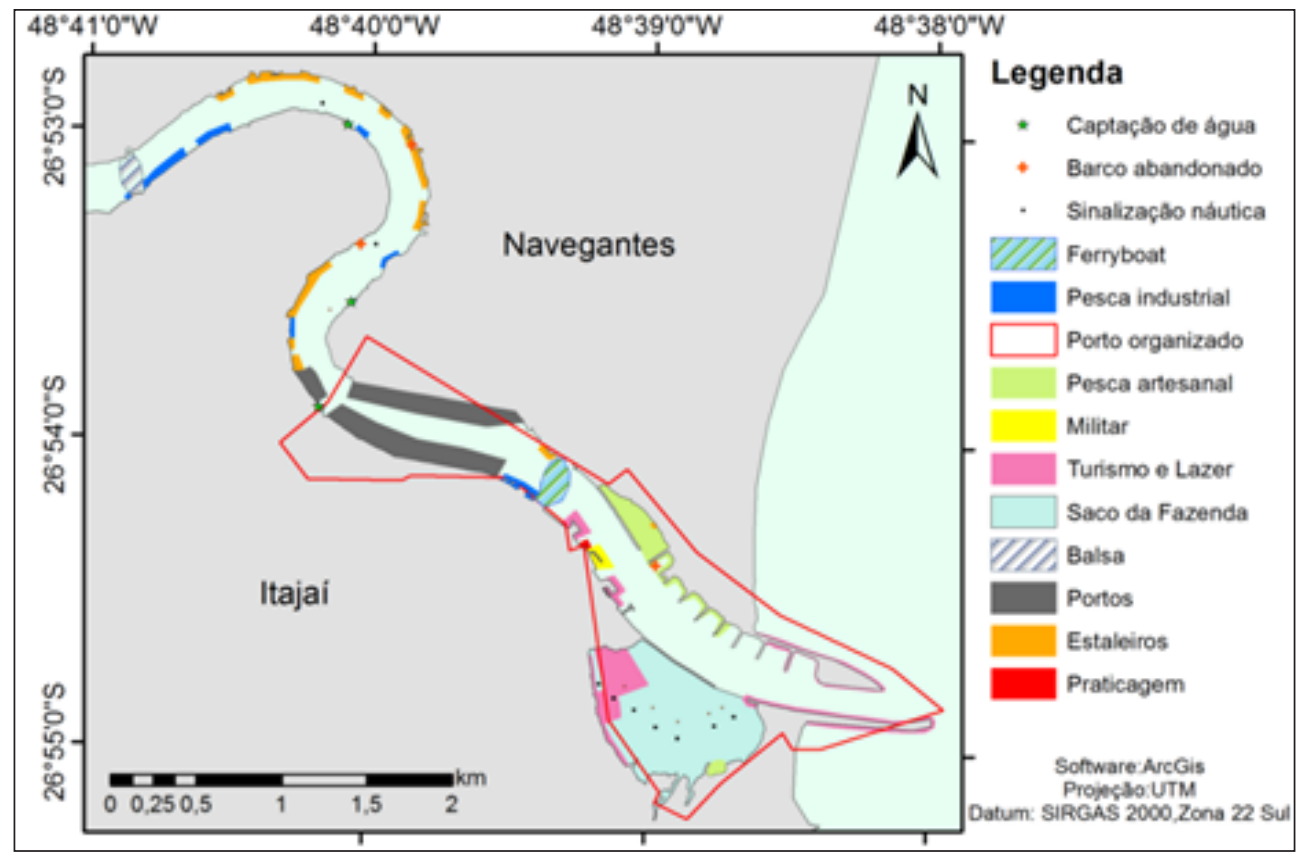

FIGURA 4 - Mapa temático de uso e ocupação da zona aquática do setor 2.

calizar-se fora do porto organizado, nos termos do art. $2^{\circ}$, inciso IV, da Lei $\mathrm{n}^{\mathrm{o}} 12.815 / 2013$. Todavia, o Porto de Navegantes, apesar de ser um terminal portuário privado, encontra-se parcialmente dentro dessa poligonal, caracterizando-se incongruência. Nos últimos anos, a extinta Secretaria Especial de Portos da Presidência da República (SEP/PR) vinha promovendo discussões para novas propostas de poligonais, justificando que tais alterações possibilitariam uma adequação da área portuária à realidade operacional observada. Na foz do Rio Itajaí-Açu, a discussão da nova poligonal está sendo efetuada pela autoridade portuária local, porém ainda em fase inicial (Porto de Itajaí).

Na região onde se situa o Saco da Fazenda, identificou-se um conflito iminente entre diferentes atores de uma mesma esfera, no caso de turismo e lazer. De um lado, a iniciativa privada (Marina Ita- jaí), com a presença de embarcações motorizadas de esporte e recreio de grande porte (lanchas, veleiros e iates), e, de outro, a sociedade civil organizada (Associação Náutica de Itajaí - ANI), com embarcações miúdas. AANI possui, em seu escopo, por meio do Projeto Navegando pela Cidadania, trabalhos de educação de crianças e jovens, principalmente por meio da prática de esportes náuticos como remo e vela. Essas diferentes abordagens de uso em áreas muito próximas, sem delimitações físicas bem definidas e claras, propiciam conflitos e problemas em escala local.

\subsubsection{Setor 3 (Área externa)}

A Zona de Uso Aquaviário e Portuário de Itajaí (ZUAP) foi classificada segundo o zoneamento do Plano Estadual e Gerenciamento Costeiro de Santa 
Catarina (GERCO, 2009), o qual delimitou a referida área em função do uso portuário e de tráfego de embarcações. Na Figura 5, pode-se observar que as regiões de bota-foras, que corresponde à área de despejo de material dragado (Porto de Itajaí - área 1:

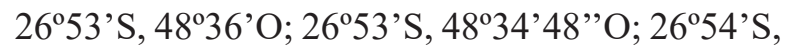

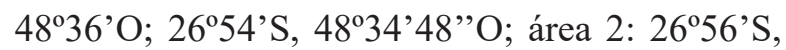

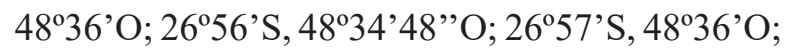
$26^{\circ} 57^{\prime} \mathrm{S}, 48^{\circ} 34^{\prime} 48^{\prime \prime} \mathrm{O}$ ), e a área de fundeio, que corresponde ao local onde os navios lançam âncora (Porto de Itajaí - Resolução $n^{\circ}$ 07/2014 - área $48^{\circ} 30^{\prime} \mathrm{O}, 26^{\circ} 56^{\prime} \mathrm{S}$; 4832, 5' O, 26 $6^{\circ} 56,5^{\prime} \mathrm{S}$; 48³2,5O, $26^{\circ} 54^{\prime}$ 'S), estão fora dessa classificação. Apenas o ponto onde embarca o profissional que conduz os navios mercantes durante a sua navegação em águas restritas nas entradas e saídas dos portos, denominado prático, está dentro da ZUAP (Ponto: $\left.26^{\circ} 55^{\prime} \mathrm{S}, 48^{\circ} 34^{\prime} \mathrm{O}\right)$. Portanto, as análises em relação à zona externa apresentam conflitos legislativos, provavelmente devido à falta de compreensão entre os atores envolvidos, constituindo-se um conflito institucional importante de ser compreendido.

$\mathrm{Na}$ área externa, também foi identificado um conflito de uso entre a pesca artesanal e a autoridade portuária. Atualmente, há uma ação civil pública na Justiça Federal (Processo $n^{\circ}$ 500458633.2012.404.7208), no bojo da qual três colônias de pescadores $(\mathrm{Z6}, \mathrm{Z36}, \mathrm{Z7})$ relatam que a atividade de dragagem do rio efetuada pela autoridade portuária vem ocasionando sérios prejuízos para a pesca. Esse fato está configurado, pois as áreas de bota-foras são as mesmas onde ocorre a pesca de arrasto de camarão, ou seja, ocorrem, na mesma área, usos incompatíveis e que devem ser sujeitos a um ordenamento territorial em escala local (Figura 5).

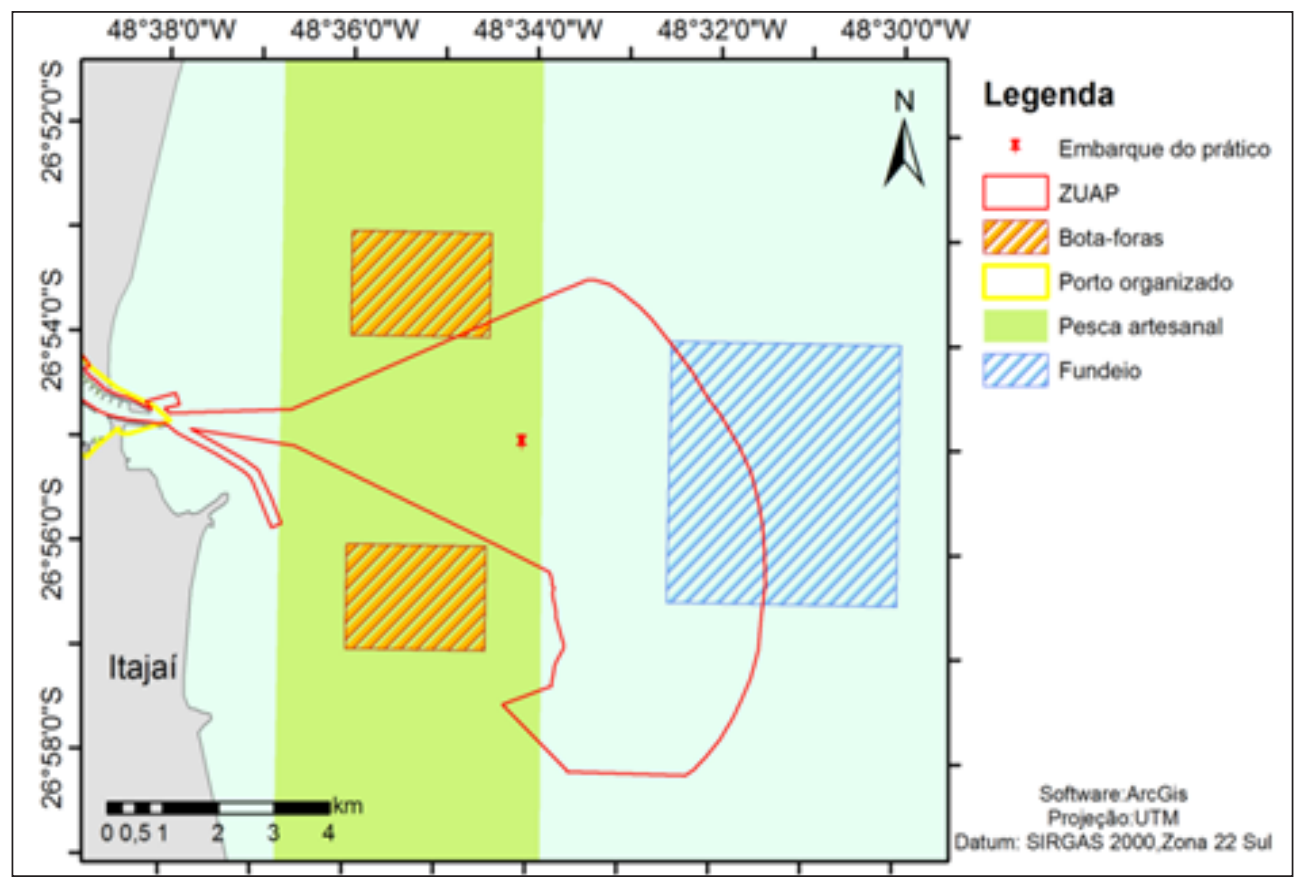

FIGURA 5 - Mapa temático e uso e ocupação da zona externa. 


\subsection{Análise das margens do Rio Itajaí-Açú}

O Código Florestal prevê, no Regime de Proteção das Áreas de Preservação Permanente, em seu art. $8^{\circ}$, que:

[...] a intervenção ou a supressão de vegetação nativa em Área de Preservação Permanente (como no caso as margens de rio) somente ocorrerá nas hipóteses de utilidade pública, de interesse social ou de baixo impacto ambiental previstas nesta Lei.

Considera-se, portanto, que as áreas sem cobertura vegetada apresentadas na Figura 6 enquadram-se nessa lei. Entretanto, é importante ponderar que a lei em questão é federal, sendo que as leis municipais podem ser mais restritivas.

A margem do Rio Itajaí-Açu na circunscrição do Município de Itajaí, em grande parte de sua extensão (excluindo-se apenas a região do Saco da Fazenda), é classificada como Macrozona de Proteção Ambiental, conforme o Plano Diretor do
Município de Itajaí (Lei Complementar no 94/2006). Entretanto, podemos observar na Figura 6 que essa mesma área quase não apresenta cobertura vegetada, ou seja, é uma área urbanizada que possui sua relação de uso direto com o rio consolidada. Em contrapartida, a Lei Complementar no 215/2012, que institui normas para o código de zoneamento, parcelamento e uso do solo do Município de Itajaí, classifica grande parte de suas áreas de margens como Macrozonas de uso especial, mais especificamente como Zona Pesqueira e Naval, diferentemente da classificação de Macrozonas proposta pelo Plano Diretor. A Lei n ${ }^{\circ} 215 / 2012$, em seu art. $1^{\circ}$, faz alusão de sua conformidade com o Plano Diretor do Município, porém, não é o que se observa, ou seja, há contradições dentro de legislações municipais. Fato é que a incongruência entre as legislações, que deveriam ser complementares entre si, modifica completamente as permissões de zoneamento e uso do solo na região (Schneider \& Ruschel, 2015).

Para as margens, em relação ao Município de Navegantes, apenas uma pequena parcela, região

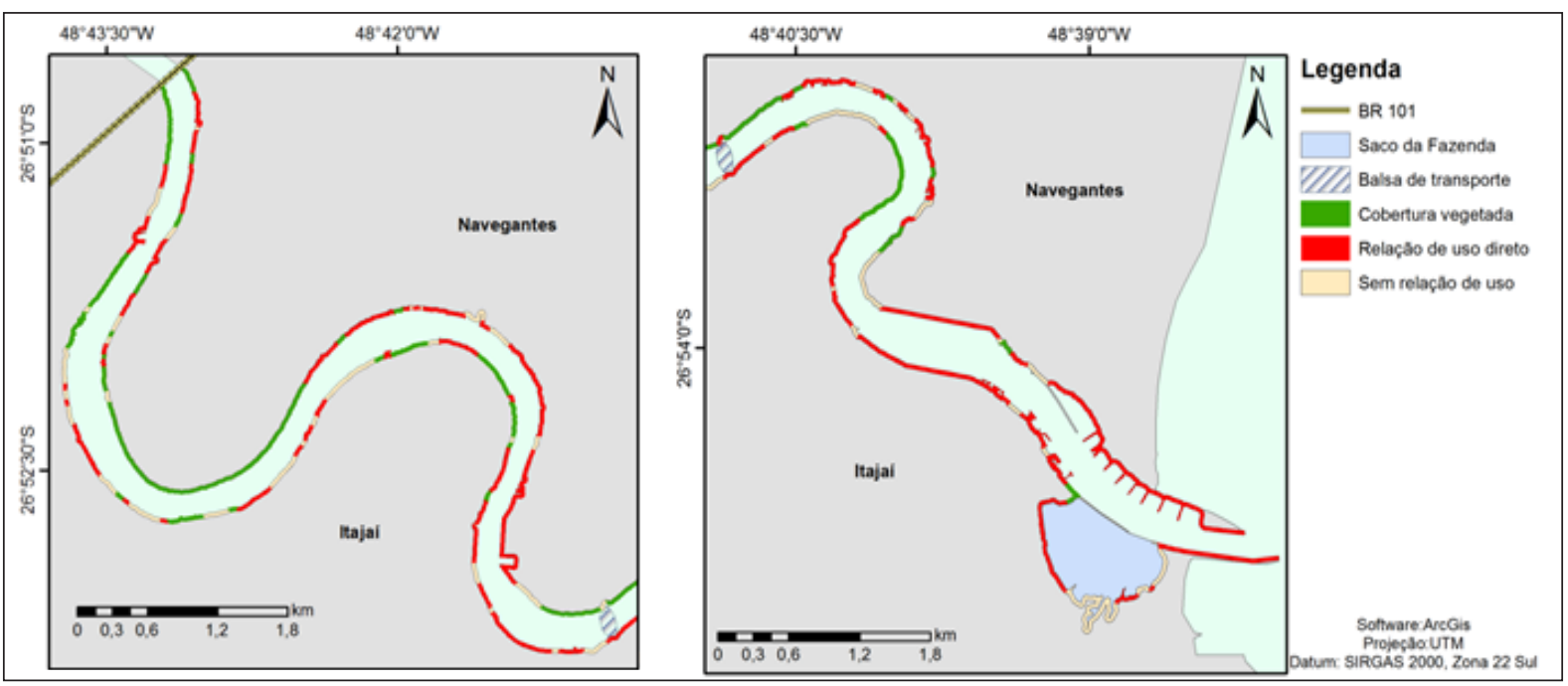

FIGURA 6 - Mapas temáticos de uso e ocupação das margens. 
nas proximidades da balsa, foi classificada como de proteção ambiental conforme seu plano diretor (Lei Complementar $n^{\circ}$ 55/2008). Atualmente, essa área ainda se encontra preservada e com a presença de vegetação, em conformidade com a legislação (Figura 6).

A compreensão do estado atual das margens, assim como das legislações incidentes, é imprescindível para o sucesso na implementação do PEM no estuário, que tem o intuito de compatibilizar os diferentes usos, garantindo-se, assim, o ordenamento territorial sem conflitos (Tuda, et al., 2014).

\subsection{Percepção dos atores ao Planejamento Espacial Marinho na ZUAP}

Na presente análise, o uso de entrevistas foi fundamental para avaliar os conflitos existentes por meio da percepção dos diferentes atores que atuam no estuário. Entende-se o termo percepção como uma combinação dos sentidos no reconhecimento de um objeto (Marin, 2008). Importante destacar que a interação entre a ciência, a sociedade e o poder público constitui uma ferramenta importante para otimizar qualquer ação de planejamento e gestão. As entrevistas demonstram-se, portanto, como ferramentas de grande suporte para o desenvolvimento de um PEM local. Como citado por Pomeroy \& Douvere (2008), é a forma de as partes interessadas serem envolvidas no processo e refletirem sobre a atual complexidade da realidade.

Tanto os órgãos governamentais quanto a iniciativa privada e entidades integrantes da sociedade civil organizada que apresentavam algum tipo de relação e/ou competência direta ou indireta com a ZUAP (Tabela 4) foram entrevistados, tendo como foco instituições dos setores que interagem no baixo estuário do Rio Itajaí-Açú.
TABELA 4 - Listagem com a relação de uso ou competência das instituições envolvidas na ZUAP.

\begin{tabular}{|c|c|}
\hline Relação e/ou competência & Instituições envolvidas \\
\hline $\begin{array}{l}\text { Educação ambiental, ensino e } \\
\text { pesquisa }\end{array}$ & ANI, IFSC, Univali, Cepsul \\
\hline Fiscalização & Ibama, Famai, Fumam, SPU \\
\hline Reparo e Construção Naval & $\begin{array}{l}\text { Maccarini, Detroit, Kalmar, } \\
\text { Navship }\end{array}$ \\
\hline Gestão da pesca & $\begin{array}{l}\text { Secretaria de Pesca de Itajaí, } \\
\text { Secretaria de Meio Ambiente } \\
\text { Agricultura e Pesca Navegantes }\end{array}$ \\
\hline Licenciamento & Fumam, Famai \\
\hline Apoio ao tráfego aquaviário & $\begin{array}{l}\text { Itajaí e Navegantes Práticos e } \\
\text { Serviços de Praticagem, Saam } \\
\text { Smit, Radio Costeira }\end{array}$ \\
\hline Turismo e Lazer & Marina Itajaí, ANI \\
\hline Transporte de carga & $\begin{array}{l}\text { Portonave, Porto de Itajaí, } \\
\text { Braskarne }\end{array}$ \\
\hline $\begin{array}{l}\text { Comércio e indústria do } \\
\text { pescado }\end{array}$ & $\begin{array}{l}\text { Sindipi, Gomes da Costa, } \\
\text { Kowalsky }\end{array}$ \\
\hline Apoio náutico & Anjos do mar, Ecosorb \\
\hline $\begin{array}{l}\text { Segurança da navegação, } \\
\text { Salvaguarda da vida humana, } \\
\text { Prevenção à poluição }\end{array}$ & $\begin{array}{l}\text { Delegacia de Portos e Costas de } \\
\text { Itajaí }\end{array}$ \\
\hline $\begin{array}{l}\text { Transporte de veículos e } \\
\text { passageiros }\end{array}$ & $\begin{array}{l}\text { Empresa de navegação de Santa } \\
\text { Catarina }\end{array}$ \\
\hline
\end{tabular}

Em relação ao perfil dos entrevistados, cerca de $40 \%$ possuem nível superior completo e $56 \%$ possuem alguma pós-graduação. O tempo médio que o entrevistado trabalha para a empresa sobre a qual representou é de nove anos. Esse fato reflete dados confiáveis sobre a realidade da região e a relação entre a instituição e o território analisado, pressupostos de sua inserção nas questões do ordenamento do baixo estuário do Rio Itajaí-Açu. No entanto, a maior parte dos entrevistados desconhece o termo Planejamento Espacial Marinho (76\%), porém, após explicação do conceito, 97\% consideraram-no importante e $93 \%$ entenderam que deve ser implementado na região. Respostas negativas à implementação e importância, citadas apenas pela inciativa privada, foram justificadas pelo receio do incremento da burocracia e de custos nas fases de licenciamento. Pouco mais da metade 
dos entrevistados (52\%) não participa de nenhum conselho gestor e cerca de $70 \%$ participa ou participou recentemente de projeto, programa ou plano no âmbito do baixo estuário (Tabelas 5 e 6).

TABELA 5 - Participação das instituições entrevistadas em conselhos de gestão e/ou em projeto, planos ou programas no contexto da ZUAP. G (Agências governamentais), P (Iniciativa Privada), S (Sociedade Civil Organizada).

\begin{tabular}{ccccc}
\hline & Conselhos de gestão & \multicolumn{2}{c}{$\begin{array}{c}\text { Projeto, Plano ou } \\
\text { Programa }\end{array}$} \\
\cline { 2 - 5 } & Sim & Não & Sim & Não \\
\hline G & 7 & 5 & 9 & 3 \\
P & 4 & 9 & 7 & 6 \\
S & 3 & 1 & 4 & 0 \\
Total \% & $\mathbf{4 8}$ & $\mathbf{5 2}$ & $\mathbf{6 9}$ & $\mathbf{3 1}$ \\
\hline
\end{tabular}

TABELA 6 - Lista dos Conselhos de gestão, Projetos, Planos e Programas citados nas entrevistas.

\begin{tabular}{ll}
\hline \multicolumn{1}{c}{ Conselhos de gestão } & Projeto, Planos e Programas \\
\hline *Conselho Municipal de & *Projeto Orla \\
Educação & *Projeto Juntos pelo Rio \\
*Conselho da Autoridade & *Projeto Limpando o Rio \\
Portuária & *Programa Navegando pela \\
*Conselho Municipal de Meio & cidadania \\
Ambiente & *Programa de Monitoramento \\
*Comitê da Bacia do Rio Itajaí & Ambiental do Porto \\
*Conselho de Gestão do Saco & *Programa de Monitoramento \\
da Fazenda & de Praias \\
*Conselho Municipal de & *Plano de área \\
desenvolvimento rural e & *Plano de ajuda mútua \\
pesqueiro de Navegantes & *Plano de Desenvolvimento e \\
& Zoneamento \\
& *Projeto de dragagem de \\
& aprofundamento do canal \\
\hline
\end{tabular}

Conforme Gohn (2001), os conselhos gestores são canais de participação que possibilitam a interlocução entre a população e o poder público estatal, sendo, portanto, instrumento mediador e negociador entre esses atores ou setores da sociedade. Logo, o fato de a maioria dos atores que atuam no estuário do Rio Itajaí-Açú não participarem de nenhum conselho gestor reflete a deficiência de meios para alcançar uma gestão integrada e participativa local. Há uma imensa dificuldade em se promover a par- ticipação em conselhos e, sobretudo, de quebrar a apatia e a relutância quanto à participação, em função do descrédito nas instituições responsáveis pela tomada de decisão, como alerta Jacobi (2003). É necessário ajustar realisticamente a concepção sobre o papel que os conselhos exercem na democratização e admitir que esses conselhos são relevantes para a democracia participativa e para a formulação de políticas públicas efetivas (Tatagiba, 2005).

É relevante destacar que apenas o Projeto Orla e o Plano de Desenvolvimento e Zoneamento abordam questões de ordenamento territorial e irão auxiliar diretamente na confecção de um PEM local, entretanto, ambas iniciativas são incipientes na questão de ordenamento na porção aquática.

Com o intuito de embasar os fins para aplicação do PEM local (Passo 1, Figura 2), questionou-se sobre quais seriam os principais problemas da ZUAP, sendo que foram citados 16 distintos problemas existentes na região estudada (Tabela 7). A maioria dos países que obtêm sucesso na implementação do PEM o fez a partir da necessidade em resolver determinados problemas, existentes ou previstos, problemas que podem estar relacionados com economia e desenvolvimento ou com a conservação do meio ambiente (Ehler \& Douvere, 2009). Fica evidente, portanto, que é preciso implementar um PEM no estuário do Rio Itajaí-Açú como forma de minimizar os diversos problemas; além disso, essa ferramenta pode promover discussões a respeito das possíveis soluções para os problemas já listados.

Ainda seguindo o Passo 1 da metodologia de Euler \& Douvere (2009), buscou-se avaliar como as instituições estariam relacionadas ao PEM no local. De acordo com Ehler \& Douvere (2009), o planejamento sem implementação é estéril e a implementação sem planejamento é uma receita para o fracasso. Portanto, o desenvolvimento do PEM sugere dois tipos de autoridade: autoridade para 
TABELA 7 - Lista dos problemas existentes dentro da ZUAP.

\begin{tabular}{ll}
\hline $\begin{array}{c}\text { Conservação do Meio } \\
\text { Ambiente }\end{array}$ & \multicolumn{1}{c}{ Econômico e desenvolvimento } \\
\hline *Poluição & *Excesso de tráfego aquaviário \\
*Ocupação desordenada & *Falta de organização na cessão de uso \\
das margens & *Preço abusivo do ferry boat \\
*Capivara nas margens & *Roubo de embarcações de pesca \\
*Extração de areia & *Fechamento de barra \\
*Pesca ilegal & *Atual bacia de evolução (pequena) \\
*Dragagem & *Enchentes \\
& *Falta de diálogo entre atores \\
& *Descumprimento das normas \\
& (legislação) \\
& *Falta de dragagem \\
\hline
\end{tabular}

planejar e autoridade para implementar (Ehler \& Douvere, 2009). A grande maioria das instituições entrevistadas (93\%) participaria de discussões para realização de um PEM na região, porém, apenas $55 \%$ prontificaram-se a implementar (Tabela 8 ). A principal justificativa para a negativa da implementação pela iniciativa privada foi o fato de não considerarem que o PEM esteja inserido no escopo do trabalho de sua instituição. As agências governamentais que não se prontificaram pela implementação mencionaram que este planejamento deveria ser feito nas esferas governamentais superiores (estaduais e federais). As principais instituições citadas para efetivamente implementar o planejamento regional foram a Autoridade Marítima (Delegacia da Capitania do Portos de Itajaí), Autoridade Portuária local, Fatma, Ibama e Univali. O papel das autoridades portuária e marítima é de regulamentação e fiscalização, já o papel dos órgãos ambientais é de monitoramento e fiscalização ambiental e o papel da universidade é de ensino, pesquisa e extensão. Entende-se, portanto, que todas as instituições citadas são complementares na construção do PEM, porém, cada qual em sua posição. Relevante destacar que um dos papéis da academia é de levar a informação à sociedade e aos órgãos competentes sobre novos modelos de gestão, disseminando o conhecimento e auxiliando, portanto, na construção do PEM (Ry- nes et al., 2001). A função de implementar o PEM deve estar associada, portanto, às instituições que são responsáveis pelas regulamentações, como, no caso, a Autoridade Marítima e/ou Portuária, sendo que as demais instituições aplicariam esforços no planejamento e execução.

Importante contextualizar que atualmente, em âmbito nacional, as discussões sobre a implementação do PEM ocorrem no Grupo Interministerial para o Gerenciamento Costeiro Integrada (Gi-GER$\mathrm{CO})$, vinculado à Comissão Interministerial dos Recursos do Mar (CIRM). Como marco nacional relevante, pode-se citar que, em novembro de 2014, realizou-se a Jornada de Gerenciamento Costeiro e Planejamento Espacial Marinho pelo Ministério do Meio Ambiente em Brasília. A partir das discussões desse evento, foram apontadas as principais barreiras e desafios para avançar no planejamento e implementação do PEM no Brasil.

TABELA 8 - Respostas das instituições sobre diferentes formas de envolvimento no PEM. G (Agências governamentais), P (Iniciativa Privada), S (Sociedade Civil Organizada)

\begin{tabular}{ccccc}
\hline & \multicolumn{2}{c}{$\begin{array}{c}\text { Participaria de } \\
\text { discussões do PEM }\end{array}$} & \multicolumn{2}{c}{$\begin{array}{c}\text { Participaria da } \\
\text { Implementação do PEM }\end{array}$} \\
\cline { 2 - 5 } & Sim & Não & Sim & Não \\
\hline G & 12 & 0 & 9 & 3 \\
P & 11 & 2 & 6 & 7 \\
S & 4 & 0 & 1 & 3 \\
Total $\%$ & $\mathbf{9 3}$ & $\mathbf{7}$ & $\mathbf{5 5}$ & $\mathbf{4 5}$ \\
\hline
\end{tabular}

O PEM deve ser orientado por um conjunto de princípios (Passo 3, Figura 2) que: (a) determinam a natureza e as características do processo; e (b) refletem os resultados que se pretende alcançar. Os princípios podem ser derivados de uma série de fontes, incluindo os tratados internacionais e acordos, políticas e legislação nacional ou demais exemplos de boas práticas (Ehler \& Douvere, 2009). Para este estudo, foram selecionados oito princípios (Tabela 9). O princípio da transparência foi citado como o 
TABELA 9 - Lista de princípios e suas descrições.

\begin{tabular}{ll}
\hline Princípio & Descrição \\
\hline Prevenção & Trata das ações antecipatórias para proteger a saúde dos ecossistemas tendo o conhecimento do estado atual. \\
Precaução & Trata das ações antecipatórias para proteger a saúde dos ecossistemas sem o conhecimento do estado atual. \\
Integração & Trata da integração entre os níveis de governo e sociedade. \\
Sustentabilidade & O ecossistema estuarino deve permanece em uma condição que garanta o uso continuado. \\
Poluidor pagador & Os custos e medidas para prevenir e combater a poluição devem ser suportados pelo poluidor. \\
Restauração & Se o ambiente está danificado, este deve ser restaurado à condição original tanto quanto possível. \\
Segurança da navegação & Princípio no qual se baseiam as normas do RIPEAM (Regulamento Internacional para Evitar Abalroamentos \\
Transparência & no Mar). \\
\hline
\end{tabular}

mais relevante por $73 \%$ das instituições, seguido pelos da prevenção, sustentabilidade e segurança da navegação, que registraram $66 \%$. O princípio da precaução foi citado como pouco relevante $(10 \%)$, o que se deve ao fato de que as instituições consideram importante ter conhecimento sobre as condições atuais do ambiente em questão, motivo que as induziu a citar o princípio da prevenção como muito relevante.

Ao identificar atributos ecológicos que são necessários para manter a saúde do ecossistema e colocá-los na vanguarda, ou seja, inseri-los como princípios relevantes, o processo de PEM irá avançar, fornecendo uma base científica forte que pode ser acoplada aos princípios socioeconômicos e de governança, objetivando alcançar o desenvolvimento sustentável (Foley et al., 2010). Os princípios de prevenção e sustentabilidade, destaques nesta pesquisa, conjeturam a noção de saúde dos ecossistemas, mencionada por Foley et al. (2010).

Para que o ordenamento do espaço marítimo seja bem-sucedido, uma abordagem baseada em temas principais (Passo 3, Figura 2) hierarquizados é indispensável. Os setores da pesca (76\%), tráfego aquaviário (62\%), portuário $(69 \%)$, do meio ambiente $(80 \%)$ e de estaleiros (59\%) foram citados como temas muito relevantes por grande parte dos entrevistados. Em contrapartida, o setor da minera- ção foi considerado pouco relevante $(38 \%)$ ou até mesmo que não deveria ser considerado (18\%) para uma futura implementação de um PEM na região. A prioridade entre temas deve ser definida, em parte, pelas partes interessadas no planejamento, assim como feito nesta pesquisa. No entanto, é importante destacar que os objetivos, que se correlacionam diretamente com os temas, para qualquer plano de gestão, devem também estar de acordo com as políticas mais amplas. Conflitos entre mandatos ou conjuntos de objetivos podem prejudicar seriamente os processos de planejamento marinhos (Peterson et al., 2005). O plano diretor do Município de Itajaí menciona que o município deve procurar integrar e racionalizar as atividades portuárias entre Itajaí e Navegantes usando, de forma conjunta e adequada, o desenvolvimento econômico da região da foz do Rio Itajaí-açú e a capacidade naval do rio (art. 20 da Lei Complementar $n^{\circ}$ 94, de 22 de dezembro de 2006). Assim sendo, para a região do baixo estuário do Rio Itajaí-Açú, há concordância entre objetivos das políticas e princípios citados pelos atores envolvidos.

Alguns lugares no âmbito do sistema marinho têm uma importância muito maior do que outros para determinadas espécies, ecossistemas ou processos. Ter o conhecimento de quais são os lugares mais importantes para conservar e dos lugares 
compatíveis com o desenvolvimento é central para a eficácia de um PEM (Ehler \& Douvere, 2009). Dos entrevistados, $45 \%$ consideraram a delimitação de áreas com a finalidade de conservação importante para região (Passo 5.2, Figura 2). Essas instituições mencionaram as margens com cobertura vegetada (50\%) e o Saco da Fazenda (50\%) como áreas de relevância biológica. Importante destacar que o Saco da Fazenda já é uma Área de Preservação Ambiental (APA) (Decreto 8.513/2008), com seu devido plano de manejo (FAMAI, 2014), ao passo que as margens do Rio Itajaí-Açú são consideradas áreas de Área de Preservação Permanente (Lei n ${ }^{\circ} 12.65 / 2012$ ), ou seja, ambas as áreas já estão contempladas por uma determinada regulamentação voltada à preservação.

No que se refere ao conflito no âmbito do baixo estuário, cerca de $80 \%$ das instituições entrevistadas citou a existência de algum envolvimento em algum tipo de conflito (Passo 5.2, Figura 2). A Agenda Ambiental Local do Porto de Itajaí (2012) menciona que há conflitos potenciais entre as operações do porto e a ecologia local. As áreas do canal de acesso, da bacia de evolução e do fundeio do Porto são significativamente modificadas, especialmente pela remoção/adição de sedimentos, o que altera o ambiente natural (conflito homem-ambiente). Além disso, pesquisas sobre pesca industrial, realizadas recentemente, consolidaram a região de Itajaí e Navegantes como a maior produtora de pescados de origem marinha do país (UNIVALI/CTTMAr, 2013), acarretando conflitos entre aqueles que utilizam as vias de acesso ao Porto de Itajaí (conflito homem-homem).

As análises abordadas nas seções anteriores baseiam-se no enfoque das primeiras etapas do ciclo da metodologia de PEM (Ehler \& Douvere, 2009) (Figura 2), de modo semelhante ao que se realiza em outras metodologias clássicas de gestão que focam o diagnóstico em seus primeiros ciclos
(Polette \& Silva, 2003). Relevante destacar que um diagnóstico robusto é um importante passo para o êxito de uma política de gestão. Portanto, o presente diagnóstico, fundamentado também na percepção dos atores, destaca que a região do baixo estuário do Rio Itajaí-Açú apresenta múltiplos serviços ecossistêmicos numa escala espacial pequena, o que explicita o alto grau de complexidade e necessidade da abordagem do PEM nessa região.

\section{Considerações finais}

Artigos recentes que utilizam a metodologia em PEM focam alguns setores (e.g Prestelo \& Vianna, 2016, focado na pesca artesanal; Dunstan et al., 2016, focado na conservação da biodiversidade), sendo que a maioria dos estudos em áreas costeiras analisam prioritariamente o setor pesqueiro e seus aspectos ambientais, principalmente em razão de esses estudos serem conduzidos dentro de áreas protegidas e geralmente focadas nos conflitos com a atividade de pesca e vice-versa (Tammi \& Kalliola, 2014). Tal fato ocorre devido à complexidade do $P E M$ e às diferentes escalas territoriais adotadas nas pesquisas. Abordagens locais em PEM (Longdill et al., 2008; Le Tixerant et al., 2010) são muito utilizadas em áreas com muitos conflitos, como geralmente é o caso em estuários.

Portanto, a presente pesquisa aderiu à escala espacial local, buscando entender o estuário como uma unidade territorial geográfica para o PEM. Gilliland \& Laffoley (2008) sugerem que é melhor aderir a uma abordagem hierárquica, focando diferentes questões ou detalhes em cada nível, ou seja, uma abordagem aninhada irá fornecer o arranjo mais eficaz e menos complicado. Com efeito, a adesão à escala local de análise permitiu que este trabalho abordasse diversos setores, como o setor portuário, 
pesqueiro, construção e reparo naval, turismo e lazer, transporte de passageiros, mineração, além do uso militar. Esse fato permitiu que os resultados atingissem elevado nível de detalhamento das informações, trazendo robusteza ao diagnóstico.

A abordagem da pesquisa espacial de dimensões sociais sobre ambientes costeiros/marinhos, utilizada neste trabalho, tem progredido significativamente ao redor do mundo (Koehn et al., 2013), sendo que seus resultados se revelaram mais elucidativos nesta pesquisa. Contribuições que abordam a informação geográfica em pesquisa participativa das zonas costeiras têm grande potencial para preencher a lacuna entre pesquisa e gestão da zona costeira (Gourmelon, 2014). Entretanto, é importante ressaltar que o PEM é muito mais do que coleta de informações e produção de mapas (Mazzer, 2005). Por esse motivo, adotou-se uma metodologia que buscou unir tanto a produção de mapas como também as questões de percepção do ambiente entre os diferentes setores envolvidos, no intuito de que esse conjunto de informações possa efetivamente trazer os diversos benefícios preconizados pelo PEM.

Este trabalho foi desenvolvido no meio acadêmico, devendo servir de base para uma discussão mais ampla no âmbito do estuário, por meio de seminários, mesas redondas, entre outros, a fim de levar à sociedade e aos governos as potencialidades do PEM como instrumento de apoio à gestão. Importante destacar que a comunicação entre a ciência e a sociedade constitui uma ferramenta relevante para otimizar qualquer planejamento e gestão (Opdam, 2010). Assim, quaisquer incentivos para melhorar as discussões e auxiliar a compreensão de várias opiniões dos interessados (tomadores de decisão, especialistas, público em geral) envolvidos no planejamento local devem ser promovidos.
Portanto, o verdadeiro desafio para a política bem-sucedida em PEM no âmbito do estuário do Rio Itajaí-Açú encontra-se na montagem de todas as peças do quebra-cabeça, promovendo a conciliação entre investigação científica e soluções práticas. Reconhecer as diferenças entre cientistas e formuladores de políticas é um passo importante em direção a uma melhor utilização da ciência na formulação de políticas, além de melhorar as chances de implementação. Ciência e elaboração de políticas são muito diferentes, mas podem e devem ser complementares (Plasman, 2008).

Os Municípios de Itajaí e Navegantes apresentam seu desenvolvimento econômico relacionado diretamente com o setor náutico, marítimo e naval. A exemplo, pode-se citar a instalação da Portonave, em 2008, no Município de Navegantes, e da Marina, em 2015, no Município de Itajaí o que teve como efeito o aumento do tráfego de embarcações. Importante mencionar que a maioria dos conflitos que envolvem áreas rasas adjacentes às áreas terrestres ocorre devido à intensificação do tráfego aquaviário, enfatizando-se a relação entre o crescimento de múltiplos usos em estuários e o desenvolvimento costeiro. Esse fato reflete a necessidade de consolidação de uma política espacial baseada também no desenvolvimento terrestre costeiro (Tuda et.al., 2014). No Brasil, há o Projeto Orla, que tem como objetivo otimizar o ordenamento dos espaços litorâneos sob domínio da União, um exemplo que busca aproximar as políticas ambiental, urbana e patrimonial (Oliveira \& Nicolodi, 2012). Esse projeto participativo foi realizado no Município de Itajaí e constituiu um primeiro passo para o avanço da gestão costeira integrada para a região. Entretanto, compreende apenas até dez metros de profundidade na zona aquática (Decreto 5.300/2004), por isso, é um projeto de apoio ao desenvolvimento de um PEM local. 
Fica evidente que, no baixo estuário do Rio Itajaí-Açu, há o envolvimento de múltiplos setores na utilização dos recursos. É provável que os conflitos entre os setores se tornem cada vez mais acirrados devido ao acelerado desenvolvimento econômico da região. Assim sendo, devem ser desenvolvidos mecanismos de gestão de conflitos adaptáveis às particularidades locais. A estrutura de PEM aqui aplicada fornece uma ferramenta útil para os gestores costeiros e partes interessadas locais para a tomada de decisões onde se sabe que existem conflitos. Além disso, este estudo pode ser considerado como um primeiro passo para o desenvolvimento de um plano de uso múltiplo no âmbito do baixo estuário do Rio Itajaí-Açu.

A originalidade desta metodologia reside em favorecer uma abordagem de análise territorial de baixo custo, além de proporcionar a oportunidade de integrar uma visão intersetorial de desenvolvimento da atividade humana em estuários, com o objetivo de fundamentar instrumentos de gestão, como, no caso, um PEM local. Os procedimentos

\section{Referências}

Agardy, T. Ocean Zoning: Making Marine Management More Effective. Earthscan Pubns Ltd. United States, 228, 2010.

Archela, R. S.; Gratão, L. H. B.; Trostdorf, M. A.S. O lugar dos mapas mentais na representação do lugar. Revista Eletrônica, 13, 1, 2004. Disponível em: <www.uel.br/revistas/ uel/index/geografia/article/File/6794/6116>.

Basso, M. Embarcação afunda no Rio Itajaí-Açu em Itajaí. O Sol Diário. 2012. Disponível em: <osoldiario.clicrbs.com. br/sc/cidades/noticia/2012/12/embarcacao-afunda-no-rio-itajai-acu-em-itajai-3978233.html>. Acesso em: jun. 2016.

Bitsch, V. Qualitative Research: A Grounded Theory Example and Evaluation Criteria. Journal of Agribusiness, 23(1), metodológicos adotados nesta pesquisa são pouco usuais, logo, as oportunidades e potencialidades que podem ser geradas são estratégicas. Dada sua concepção metodológica, esses procedimentos podem ainda ser implementados também para outras regiões estuarinas que pretendam buscar o desenvolvimento ordenado.

Portanto, compreender o ambiente marinho e sua relação direta com o continente, considerar sua dinâmica ambiental e especificidades de zoneamento, fomentar a participação social e instituições do poder público são os princípios básicos para uma efetiva gestão de ambientes aquáticos visando à sustentabilidade.

\section{Agradecimento}

À Coordenação de Aperfeiçoamento de Pessoal de Nível Superior (CAPES) pela bolsa de doutorado recebida para o desenvolvimento deste trabalho.

75-91, 2005. Disponível em: $<$ http://ageconsearch.umn.edu/ bitstream/59612/2/S05-05.pdf>

Brasil. Decreto-lei $n^{\circ}$ 9.760, de 5 de setembro de 1946. Dispõe sobre os bens imóveis da União e dá outras providências. Brasília: DOU de 6.9.1946.

Brasil. Decreto $n^{\circ} 5.300$, de 07 de dezembro de 2004. Institui o Plano Nacional de Gerenciamento Costeiro - PNGC. Brasília: DOU de 08/12/2004.

Brasil. Decreto de 16 de março de 2005. Dispõe sobre a definição da Área do Porto Organizado de Itajaí, no Estado de Santa Catarina. Brasília: DOU de 17/03/2005.

Brasil. Lei $n^{\circ} 12.651$, de 25 de maio de 2012. Dispõe sobre a proteção da vegetação nativa e dá outras providências. Brasília: DOU de 28/05/2012. 
Brasil. Lei $n^{\circ} 12.815$, de 05 de junho de 2013. Dispõe sobre a exploração direta e indireta pela União de portos e instalações portuárias. Brasília: DOU de 5/6/2013.

Calado, H.; Johnson, K.; Ng, D.; Sousa, L.; Phillips, M.; Alves F. Marine spatial planning: lessons learned from the Portuguese debate. Marine Policy, 34(6), 1341-1349, 2010. doi: 10.1016/j.marpol.2010.06.007

Chang, Y.; Lin, B. Improving marine spatial planning by using an incremental amendment strategy :The case of Anping, Taiwan. Marine Policy, 68, 30-38, 2016. doi: 10.1016/j.marpol.2016.02.004

Crowder, L. B.; Osherenko, G.; Young, O. R.; Airamé, S.; Norse, E. A.; Baron, N.; Day, J. C.; Douvere, F.; Ehler, C. N.; Halpern, B. S.; Langdon, S. J.; McLeod, K. L.; Ogden, J. C.; Peach, R. E.; Rosenberg, A. A.; Wilson, J. A. Resolving Mismatches in U.S. Ocean Governance, 313, 2006. Science. doi: 10.1126/science.1129706

Douvere, F.; Maes, F.; Vanhulle, A.; Schrijvers, J. The role of marine spatial planning in sea use management: The Belgian case. Marine Policy, 31(2), 182-191, 2007. doi: 10.1016/j.marpol.2006.07.003

Dunstan, P. K.; Bax, N. J.; Dambacher, J. M.; Hayes, K. R.; Hedge, P. T.; Smith, D. C.; Smith, A. D. M. Using ecologically or biologically significant marine areas (EBSAs) to implement marine spatial planning. Ocean \& Coastal Management, 121, 116-127, 2016. doi: 10.1016/j.ocecoaman.2015.11.021

Ehler, C. Conclusions: benefits, lessons learned, and future challenges of marine spatial planning. Marine Policy, 32(5), 840-843, 2008. doi: 10.1016/j.marpol.2008.03.014

Ehler, C. Perspective: the present and future of marine spatial planning around the world. Marine Ecosystems and Management, 6(4), 4-5, 2013.

Ehler, C.; Douvere, F. Marine Spatial Planning: A stepby-step approach toward ecosystem-based management. Intergovernmental Oceanographic Comission and Man and the Biosphere Programme. IOC Manual and Guides, 53, 2009. Disponível em: <http://unesdoc.unesco.org/images/0018/001865/186559e.pdf>. Acesso em: maio 2015.

FAMAI - Fundação de Meio Ambiente de Itajaí. Plano de Manejo da Área de Proteção Ambiental (APA) do Saco da Fazenda, Itajai, SC. 2014. Disponível em: <http://famai. itajai.sc.gov.br/noticia/16493/plano-de-manejo-do-saco-
-da-fazenda-esta-disponivel-para-consulta-\#.WJisLdIrJdh> Acesso em: jan.2017.

Foley, M. M.; Halpern, B. S.; Micheli, F.; Armsby, M. H.; Caldwella, M. R.; Crain, C. M.; Prahler, E.; Rohr, N.; Sivas, D.; Beckf, M. W.; Carr, M. H.; Crowder, L. B.; Duffy, J. E.; Hacker, S. D.; McLeod, K. L.; Palumbi, S. R.; Peterson, C. H.; Regan, H. M.; Ruckelshausm, M. H.; Sandifer, P. A.; Steneck, R. S. Guiding ecological principles for marine spatial planning. Marine Policy 34, 955-966, 2010. doi: 10.1016/j.marpol.2010.02.001

Fontanella, B. J. B.; Ricas J.; Turato, E. R. Amostragem por saturação em pesquisas qualitativas em saúde: contribuições teóricas. Cadernos de Saúde Pública, 24(1), 17-27, 2008. doi: 10.1590/S0102-311X2008000100003

Gee, K.; Kannen, A.; Glaeser, B.; Sterr, H. National ICZM strategies in Germany: A spatial planning approach. In: Schernewski, G.; Löser, N. (Eds.). Managing the Baltic Sea. Coastline Reports, 2, 23-33, 2004. Disponível em: <http:// ec.europa.eu/ourcoast/download.cfm?fileID=1240>. Acesso em: maio 2016.

GERCO/SC. Programa Estadual de Gerenciamento Costeiro de Santa Catarina. 2009. Disponível em: <www.spg. sc.gov.br>. Acesso em: jun. 2014.

Gilliland, P. M.; Laffoley, D. Key elements and steps in the process of developing ecosystem-based marine spatial planning. Marine Policy, 32, 787-796, 2008. doi: 10.1016/j. marpol.2008.03.022

Gohn, M. G. Conselhos gestores e participação sociopolitica. São Paulo, 2001.

Goulart Filho, A. As respostas do Porto de Itajaí à dinâmica da economia catarinense. Revista de Economia, 34, 1, 25 49, 2008. doi: 10.5380/re.v34i1.11551>.

Gourmelon, F.; Le Guyader, D.; Fontenelle, G. A Dynamic GIS as an Efficient Tool for Integrated Coastal Zone Management. ISPRS International Journal of Geo-Information, 3, 391-407, 2014. doi: 10.3390/ijgi3020391

Halpern, B. S.; Walbridge, S.; Selkoe, K. A.; Kappel, C. V.; Micheli, F.; D'Agrosa, C. A global map of human impact on marine ecosystems. Science, 319, 948-952, 2008. doi: 10.1126/science. 1149345

Huang, W.; Corbett, J. J.; Jin, D. Regional economic and environmental analysis as a decision support for marine 
spatial planning in Xiamen. Marine Policy, 5, 555-562, 2015. doi: 10.1016/j.marpol.2014.09.006

Integrated Management Plan for the North Sea 2015 (IMPNS, 2015). Interdepartmental Directors Consultative Committee. The Netherlands. 2005. Disponível em: $<$ https:// www.noordzeeloket.nl>. Acesso em: maio.2016.

Itajaí. Decreto $n^{\circ} 8.513$, de 4 de março de 2008. Dispõe sobre a criação da unidade de conservação do Saco da Fazenda, Itajaí, 2008.

Itajaí. Lei Complementar nº 94, de 22 de dezembro de 2006. Institui o Plano Diretor de Gestão e Desenvolvimento Territorial de Itajaí, Itajaí, 2006.

Itajaí. Lei Complementar $n^{\circ} 215$, de 31 de dezembro de 2012. Institui Normas para Código de Zoneamento, Parcelamento e Uso do Solo no Município de Itajaí, Itajaí, 2012.

Jacobi, P. R. Espaços públicos e práticas participativas na gestão do meio ambiente no Brasil. Sociedade e Estado, 18(1/2), 315-318, 2003. doi: doi.org/10.1590/S010269922003000100015

Jay, S.; Klenke, T.; Janben, H. Consensus and variance in the ecosystem approach to marine spatial planning: German perspectives and multi-actor implications. Land Use Policy, 54, 129-138, 2016. doi: 10.1016/j.landusepol.2016.02.015

Jornada de Gerenciamento Costeiro e Planejamento Espacial Marinho. 2014. Disponível em: < hotsite.mma.gov.br/ jornada-gerco/>. Acesso em: fev. 2016.

Katsanevakis S.; Stelzenmüller, V.; South, A.; Sørensen, T. K.; Jones, P. J. S.; Kerr, S.; Badalamenti, F.; Anagnostou, C.; Breen, P.; Chust, G.; D’Anna, G.; Duijn, M.;Filatova, T.; Fiorentino, F.; Hulsman, H.; Johnson, K.; Karageorgis, A. P.; Kröncke, I.; Mirto, S.; Pipitone, C.; Portelli, S.; Qiu, W.; Reiss, H.; Sakellariou, D.; Salomidi, M.; Hoof, L.; Vassilopoulou, V.; Fernández, T. V.; Vöge, S.; Weber, A. Ecosystem-based marine spatial management: review of concepts, policies, tools, and critical issues. Ocean \& Coastal Management, 54(11), 807-820, 2011. doi: 10.1016/j. ocecoaman.2011.09.002

Koehn, J. Z.; Reineman, D. R.; Kittinger, J. N. Progress and promise in spatial human dimensions research for ecosystem-based ocean planning. Marine Policy, 42, 31-38, 2013. doi: 10.1016/j.marpol.2013.01.015
Le Tixerant, M.; Gourmelon, F.; Tissot, C.; Brosset, D. Modelling of human activity development in coastal sea areas. Jourrnal of Coastal Conservation, 15, 407-416, 2010. doi: 10.1007/s11852-010-0093-4

Lima, O. P.; Philips, J. W. Demarcação dos terrenos de Marinha e seus acrescidos. Revista de Direito Imobiliário, 28, 59, 166-193, 2005. Disponível em: <bdjur.stj.jus.br/ jspui/handle/2011/87561

Longdill, P. C.; Healy, T. R.; Black, K. P. An integrated GIS approach for sustainable aquaculture management area site selection. Ocean and Coastal Management, 51, 612-624, 2008. doi: 10.1016/j.ocecoaman.2008.06.010

Marin, A. A. Pesquisa em educação ambiental e percepção ambiental. Pesquisa em Educação Ambiental, 3, 1, 203222, 2008.

Mazzer, A. M. Classificação de áreas aplicadas ao Zoneamento Ecológico Econômico Costeiro-Marinho para o Programa Estadual de Gerenciamento Costeiro de Santa Catarina. In: Anais do II Congresso Brasileiro de Oceanografia, Vitória, 2005.

Mazzer, A.M. Estudo complementar para implementação do Plano de Ordenamento Náutico do Município de Florianópolis. Florianópolis. 2013.

McCook, L. J.; Ayling, T.; Cappo, M.; Choat, J. H.; Evans, R. D.; De Freitas, D. M.; Heupel, M.; Hughes, T P.; Jones, G. P.; Mapstone, B.; Marsh, H.; Mills, M.; Molloy, F. J.; Pitcher, C .R.; Pressey, R. L.; Russ, G. R.; Sutton, S.; Sweatman, H.; Tobin, R.; Wachenfeld, D. R.; Williamson, D. H.. Adaptive management of the Great Barrier Reef: a globally significant demonstration of the benefits of networks of marine reserves. Proceedings of the National Academy of Sciences, 107, 18278-18285, 2010. doi: 10.1073/pnas.0909335107

Navegantes. Lei Complementar $n^{\circ} 55$ de 22 de julho de 2008. Institui o código urbanístico, que define princípios, políticas, estratégias e instrumentos para o desenvolvimento municipal.

Oliveira, M. R. L.; Nicolodi, J. L. A gestão costeira no Brasil e os dez anos do Projeto Orla. Uma análise sob a ótica do poder público. Revista de Gestão Costeira Integrada, 12, 2012. Disponível em: <http://www.aprh.pt/rgci/pdf/rgci308_Oliveira.pdf 
Opdam, P. Learning science from practice. Landscape. Ecology, 35, 821-823, 2010. doi: 10.1007/s10980-010-9485-y

Peterson, D. L., A. Wood and J. Gardner. An Assessment of Fisheries and Oceans Canada Pacific Region's Effectiveness in Meeting its Conservation Mandate. Vancouver, B.C.: David Suzuki Foundation. 2005. Disponível em: <www. davidsuzuki.org/publications>. Acesso em: nov.2015.

Piazza, G. A.; Polette, M. Ordenación del espacio marino para buques transatlánticos en porto Belo/Santa Catarina (BR). Natural Resources, 5, 2, 2015. doi: 10.6008\%2F896

Plasman, C. Implementing marine spatial planning: A policy perspective Institute for Agricultural and Fisherie. Marine Policy, 32, 811-815, 2008. doi: 10.1016/j.marpol.2008.03.016

Polette, M. Gerenciamento Costeiro Integrado - Um proposta metodológica para a microbacia de Mariscal. Tese (Doutorado em Ecologia) - UFSCar, 1997.

Polette, M.; Marenzi, R. C.; Santos C. F. Atlas Socioambiental de Itajaí. Itajaí: Editora da UNIVALI, 2012.

Polette, M.; Silva, L.P. Gesamp, Icam e PNGC- Análise comparativa entre as metodologias de gerenciamento costeiro integrado. Ciência e Cultura, 5, 4, 2003. Disponível em: $<$ cienciaecultura.bvs.br

Pomeroy, R.; Douvere, F. The engagement of stakeholders in the marine spatial planning process. Marine Policy.32(5), 816-822, 2008. doi: 10.1016/j.marpol.2008.03.017.

Portman, M. E.; Duff, J. A.; Koppel, J.; Reisert, J.; Higgins, M.E. Offshore wind energy development in the exclusive economic zone: Legal and policy supports and impediments in Germany and the US, 37, 3596-3607,2009. Energy Policy. doi: 10.1016/j.enpol.2009.04.023

Porto de Itajaí. PDZ 2010. Disponível em: <www.portoitajai.com.br/novo $>$. Acesso em: jun. 2014.

Porto de Itajaí. Agenda Ambiental Local. Itajaí, 2012. Disponível em: < http://www.portoitajai.com.br/novo/ download.php?id=1125. > > . Acesso em: fev.2016.

Porto de Itajaí. Resolução $n^{\circ} 07$ de 08 de julho de 2014. Estabelece a delimitação da área de fundeadouro e de fundeio do Porto de Itajaí.

Porto de Itajaí. Plano Mestre. Itajaí, 2015. Disponível em: < http://www.portosdobrasil.gov.br/assuntos-1/pnpl/arquivos/ planos-mestres-sumarios-executivos/se14.pdf $>$.. Acesso em: fev. 2016.

Prestelo, L.; Viana, M. Identifying multiple-use conflicts prior to marine spatial planning: A case study of A multi-legislative estuary in Brazil. Marine Policy, 67, 83-93, 2016. doi: 10.1016/j.marpol.2016.02.001

Rorig, L.R. Usos múltiplos e qualidade das águas da Bacia do Baixo Itajaí-Açú-SC: elementos para um gerenciamento integrado. Tese (Doutorado em Ecologia e Recursos Naturais) - UFSCar, 2005.

Rynes, S.L.; Bartunek, J. M.; Daft, R. L. Across the Great Divide: Knowledge Creation and Transfer Between Practitioners and Academics, Academy of Manage Journal, 44(2), 340-355, 2001. doi: $10.2307 / 3069460$

Santa Catarina. Instrução Normativa n. 07 de 28 de março de 2014. Normas de segurança contra incêndios-Sistema hidráulico preventivo. 2014. Corpo de Bombeiros Militar. Disponível em: $<$ http://www.cbm.sc.gov.br/dat $>$. Acesso em: maio 2016.

Schneider, S.; Ruschel, C. V. A violação do princípio da proibição do retrocesso da lei ambiental na região do Canto do Morcego, Itajaí - SC. Revista Eletrônica Direito e Política, 10, 1, 2015. Disponível em: <siaiap32.univali.br

SEP - Secretaria de Portos. Portaria $n^{\circ} 414$, de 30 de dezembro de 2009. Estabelece as diretrizes, os objetivos gerais e os procedimentos mínimos para a elaboração do Plano de Desenvolvimento e Zoneamento Portuário. Brasília: DOU de 31/12/2009.

Silva, D. D. C.; Pereira Filho, J. Qualidade química da água em função de seu uso na rizicultura irrigada na região do baixo estuário do rio Itajaí. Revista de Estudos Ambientais, 12(2), 26-37, 2010. Disponível em: < http://proxy.furb.br/ ojs/index.php/rea/article/viewFile/1799/1448

Smythe, T. C. Marine spatial planning as a tool for regional ocean governance?: An analysis of the New England ocean planning network. Ocean \& Coastal Management, 135, 11 24, 2017. doi: 10.1016/j.ocecoaman.2016.10.015

Suares-de Vivero, J. L.S.; Mateos, J. C. R. The Spanish approach to marine spatial planning. Marine Strategy Framework Directive vs. EU integrated maritime policy. Marine Policy 36(1), 18-27, 2012. doi: 10.1016/j.marpol.2011.03.002 
Tammi, L.; Kalliola, R. Spatial MCDA in marine planning: experiences from the Mediterranean and Baltic Seas. Marine Policy, 48, 73-83, 2014. doi: 10.1016/j.marpol.2014.03.015

Tatagiba, L. Conselhos gestores de políticas públicas e democracia participativa: aprofundando o debate. Revista de Sociologia e Política, n 25, 2005. doi: 10.1590/S010444782005000200017
Tuda, A. O.; Stevens, T. F.; Rodwell, L. D. Resolving coastal conflicts using marine spatial planning. Journal Environmental Management, 133, 59-68, 2014. doi: 10.1016/j. jenvman.2013.10.029

UNIVALI/CTTMar. Boletim estatistico da pesca industrial de Santa Catarina - Ano 2011. Universidade do Vale do Itajaí, CTTMar, Itajaí, SC, 12, 1, 59, 2013. Disponível em: <gep.acad.univali.br>. Acesso em: abr. 2016. 